\title{
Dynamic shear fracture toughness and failure characteristics of Ti-6Al-4V alloy under high loading rates
}

\author{
Zejian Xu ${ }^{\mathrm{a}^{*}}$, Yang Han ${ }^{\mathrm{a}}$, Changzeng Fan ${ }^{\mathrm{a}}$, Xiaodong $\mathrm{He}^{\mathrm{b}}$, PJ Tan ${ }^{\mathrm{c}}$, Fenglei Huang ${ }^{\mathrm{a}}$ \\ aState Key Laboratory of Explosion Science and Technology, Beijing Institute of Technology, Beijing 100081, PR \\ China

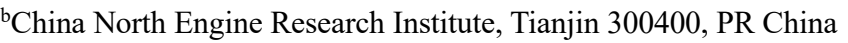 \\ cDepartment of Mechanical Engineering, University College London, Torrington Place, London WC1E 7JE, UK
}

\begin{abstract}
A novel two-bar/double-shear impact (2B/2SI) loading technique is used to study the dynamic mode II (shear) fracture characteristics of Ti-6Al-4V. The new specimen design, to be used in combination with a standard split Hopkinson pressure bar, circumvent classical limitations associated with conventional one-point impact methods. This paper presents a combined experimental-numerical approach to determining the mode II fracture toughness of Ti-6Al-4V for a broad range of loading rates between 1.10 $\times 10^{-2}-4.98 \times 10^{7}\left(\mathrm{MPa} \cdot \mathrm{m}^{1 / 2} \mathrm{~s}^{-1}\right)$. Results showed only a slight initial increase in toughness, which increases abruptly with loading rates beyond $10^{6}\left(\mathrm{MPa} \cdot \mathrm{m}^{1 / 2} \mathrm{~s}^{-1}\right)$. Fractographic examination showed distinctively different mechanisms in operation at the microscale, depending on the rate of loading. Failure is through a brittle-ductile, mixed-mode fracture under quasi-static conditions; by contrast, the fracture surface exhibited fractographic features of adiabatic shear bands (ASB) and material melting/resolidification under dynamic conditions. High-speed photography showed that both dynamic shear fracture (DSF) and ASB occurred during the same loading process. Interactions between DSF and ASB were observed to influence the dominant failure mechanism of the material at high loading rates.
\end{abstract}

Keywords: Dynamic fracture; Shear (Mode II) fracture; Adiabatic shear band; High strain rate; Hopkinson bar

\section{Introduction}

In metal forming, high-speed machining, or the blast and projectile loading of structures, a sheardominated state of stress often rises, leading to material failure by dynamic shear (mode II) fracture (or DSF, for brevity). Under dynamic conditions, the development of adiabatic shear band (or ASB) - this is often accompanied by DSF - is another important cause of failure. DSFs are material discontinuities due to cleavage and/or void coalescence whereas ASBs are highly localized plastic deformation (Arriaga and Waisman, 2017). Although fracture and shear banding are two different phenomena of distinct spatial and temporal scales, either one, or their combination, can lead to a rapid loss of load carrying capability by the material. There exists an interplay between inelastic deformation associated with shear banding and ductile fracture due to the coalescence and growth of voids - they were observed in several dynamically loaded materials (Kalthoff and Winkler, 1988; Mason et al., 1994; Zhou et al., 1996). However, the interactions (and interplay) between DSF and ASB remains hitherto unclear.

To study the failure mode that develops in shear loaded steel plates, Kalthoff $(1987,1990)$ and Kalthoff and Winkler (1988) performed cylindrical projectile impact experiments on plate

\footnotetext{
* Corresponding author. Tel.: +861068914087

E-mail address: xuzejian@bit.edu.cn (Z. Xu)
} 
specimens containing two parallel edge notches. They observed a transition in failure mode - from brittle cracking that originates from the root of the notch, and inclined at approximately $70^{\circ}$, to ASBing inclined at about $0^{\circ}$ to $-15^{\circ}$ - when the impact speed exceeded a critical value. To interpret these experimental results, Lee and Freund (1990) derived an analytical solution for the crack-tip field, where it was found that, in addition to a mode II dynamic stress intensity factor (DSIF), a negative mode I DSIF also arises because of the finite gap between the crack faces. Mason et al. (1994) employed a coherent gradient sensing (CGS) method to record the deformation field around the pre-crack tip of a maraging steel specimen, and a transition of failure mode from shear banding to fracture was also observed. Similar transition was also reported by Zhou et al. (1996). Tests on polycarbonate specimens by Ravi-Chandar (1995) revealed failure mode transitions from ductile to brittle and to ductile again as loading rate increases. Recently, Xu et al. (2020) found through experimental observations that the failure mode transition (FMT) is actually not an abrupt change, but a continuous evolving process of distinct microstructures dominated by a thermo-plastic mechanism, which provides a brand-new understanding to the mechanism of FMT.

Different techniques were employed to measure the dynamic mode II SIF ( $K_{\text {II }}$ ) of various materials. Rittel (2005) used a hybrid experimental-numerical method to determine the dynamic $K_{\text {II }}$ at the onset of adiabatic shear banding, and compared their predictions to those of Guduru et al. (2001). Xu et al. (2006) proposed a modified Hopkinson bar technique to determine the mode II dynamic fracture toughness (DFT) of two different kinds of high strength steel. In their work, the fracture initiation time was measured experimentally using strain gauges mounted on the specimen, and finite element analysis (FEA) were used to compute the dynamic $K_{\text {II. }}$. The method of caustics was employed by Liu et al. (2010) on TA15 alloy, and Miao et al. (2016) performed mode II dynamic fracture tests on TC4 alloy. Zou et al. (2017) proposed a DSF testing method based on the split Hopkinson tension bar (SHTB) technique. A modified compact tension shear (MCTS) specimen was used in their research. More recently, Xu et al. $(2018,2020)$ proposed a novel method to test dynamic mode II fracture toughness using the split Hopkinson pressure bar (SHPB) technique and a double-precracked shear fracture specimen.

Under quasi-static conditions, disk-type specimen, punch-through shear specimen, and other similar specimen types (Lin et al., 2020; Srinath et al., 1983) have been developed to create the state of pure shear at the crack tip. Under dynamic loading, a plethora of specimen geometries were designed to study the dynamic shear fracture (DSF) of materials. They include the single-sided prenotched specimen with a single notch (Mason et al., 1992; Ravi-Chandar, 1995; Zhou et al., 1996; Rittel and Maigre, 1996; Rittel et al., 1997; Mason et al., 1994; Roessig and Mason, 1998; Kalthoff and Bürgel, 2004; Rittel, 2005; Xu et al., 2006; Miao et al., 2016) and double notches (Rittel, 1998; Dong et al., 1998, 2003); double-side pre-notched specimen (Liu et al., 2010); end notched flexure specimen (Kusaka et al., 1994; Nwosu et al., 2003), center-cracked Brazilian disk (Nakano et al., 1994); pre-cracked laminate specimen (Sohn and Hu, 1996); thin plate specimen with narrow Unotch (Wen et al., 2016); compact tension shear specimen (Zou et al., 2017); cylindrical specimen with circular notches (Yao et al., 2017), etc. Different loading techniques were also employed which include the direct projectile impact (DPI) method (Ravi-Chandar, 1995; Zhou et al., 1996; Roessig and Mason, 1998; Kalthoff, 2000; Kalthoff and Bürgel, 2004), the modified Hopkinson pressure bar (MHPB) system (Nakano et al., 1994; Rittel and Maigre, 1996; Rittel et al., 1997; Rittel, 1998; 2005; Dong et al., 1998; 2003; Xu et al., 2006; Miao et al., 2016; Yao et al., 2017), the split Hopkinson tension bar (SHTB) (Wen et al., 2016; Zou et al., 2017), the drop weight tower (Mason et al., 1992; 
Liu et al., 2010), and the Charpy impact test machine (Sohn and Hu, 1996).

The one-point impact loading technique (such as the DPI and MHPB methods) is commonly used because it can achieve a high loading rate whilst avoiding the need for complicated fixtures. In the DPI technique, a relatively high loading rate can be achieved by simply increasing the projectile impact speed. However, it needs to be supplemented by additional optical set-up (such as caustics method, photoelasticity, and CGS methods) to record information related to the fracture event. By contrast, the MHPB technique is much more convenient for DSF measurements. For this method, the incident bar is in direct contact with the pre-cracked specimen without the need for a transmitter bar. The compressive pulse induced by the striker is partly transmitted to the specimen leading to mode II loading at the crack tip, and partly reflected back into the incident bar as a tensile pulse. Using the strain signals of the bar, the interface force and corresponding displacement can be determined and these are fed into a numerical model to calculate the DSIFs. In the experiments, the amplitude and duration of the incident pulse is easily controlled by varying the length and velocity of the striker bar. The rise time of the incident pulse can also be altered using an appropriate pulseshaping technique. Jiang and Vecchio (2009) described the aforesaid loading scheme as a onebar/one-point impact method. However, there are a number of disadvantages associated with this method. First, without the transmitter bar, the temporal force history acting on the distal face of the specimen cannot be measured; hence, force-equilibrium of the specimen during the loading process cannot be examined. Second, the specimen geometry gives rise to an opening displacement at the crack tip so that a pure mode II loading condition is, consequently, difficult to achieve; in fact, fracture initiates in a mixed (I-II) mode. Third, the specimen may lose contact with the bar during the loading process due to strong inertial effects in the specimen. If this is the case, the measured force and displacement of the specimen are no longer valid. Finally, in the one-bar/1PI tests, an edge-notched specimen with a relatively large volume of material is often used and, for materials with high toughness, an incident pulse of sufficiently high intensity must be generated to produce the high stress intensity required to initiate fracture in a sample, which may be limited by the elastic properties of the loading bar material.

To avoid the limitations of the one-point impact methods, the new mode II dynamic fracture experimental method (Xu et al., 2018, 2020) is adopted. In this method, the newly designed doubleprecracked shear fracture specimen is subjected to a two-bar / "double-shear impact" (2B/2SI) loading technique. Samples of Ti-6Al-4V alloy are tested using this method at different loading rates and their corresponding mode II DFTs determined using a hybrid experimental-numerical method. Fracture surfaces will be examined by metallography and fractography to elucidate the failure mechanisms in the material. The failure process of the specimen is also monitored by a high-speed photography, to study the interactions/interplay between DSF and ASB.

\section{Experiments}

\subsection{Material, specimen design and preparation}

The double-precracked shear fracture (2SF) specimen first proposed by Xu et al. (2018) was further improved for this work, see schematic in Fig. 1. The specimen has a thickness of $6 \mathrm{~mm}$, and comprises of one loading and two support ends, with each end squarely in contact with the incident and transmitter bar, respectively, in a SHPB set-up. Two parallel pre-cracks of $4 \mathrm{~mm}$ length and $0.12 \mathrm{~mm}$ width were introduced on opposite sides of the loading end (see Fig. 1) by low speed wire electrical-discharge machining (WEDM-LS). The crack tip radius is approximately $0.06 \mathrm{~mm}$. With 
this design, the traditional SHPB set-up can be used to perform the mode II fracture experiments without extraneous modifications. The compressive stress pulse applied to the top of the specimen (in contact with the incident bar) result in localised shear at the crack tips, thus giving rise to a mode II loading condition. Since the specimen is sandwiched between both the incident and transmitter bar, the force and displacement history between the specimen and the input and output interfaces can be determined simultaneously; in addition, the issue of "losing contact" is prevented since the stress waves are transmitted into the transmitter bar from the support end of the specimen.

In this work, the $2 \mathrm{SF}$ specimen is made from a commercial grade Ti-6Al-4V alloy with a chemical composition as listed in Table 1. A circular plate, of approximately $6.1-6.2 \mathrm{~mm}$ thick, was initially cut from an extruded bar stock of $100 \mathrm{~mm}$ diameter and its planar surfaces were polished to ensure they are parallel, leading to a circular plate of uniform $6 \mathrm{~mm}$ thickness. Samples were manufactured by WEDM from this plate. After that, two precracks were introduced, via low speed WEDM, into each specimen. All the specimens were machined so that their axis of symmetry is always perpendicular to the axis of the bar stock. The two ends of the specimens, in contact with the pressure bars, were also polished to ensure they are in square contact with the pressure bars at all times.

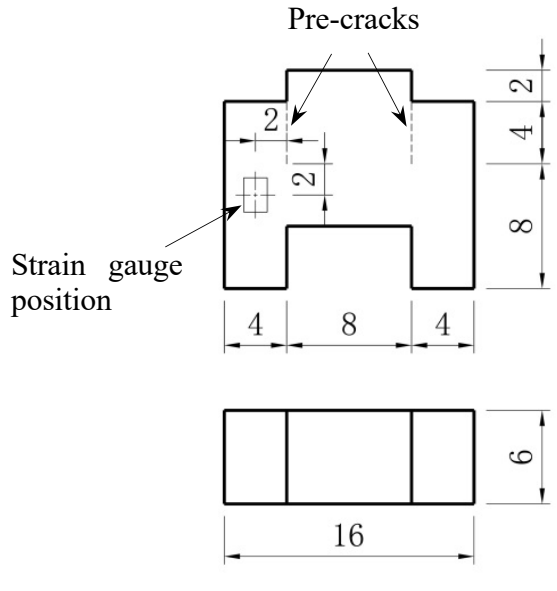

(a)
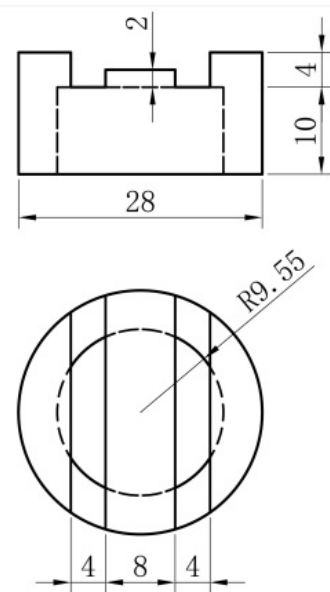

(b)

Figure 1. Schematic of the (a) 2SF sample and (b) mounting fixture in first-angle projection. All dimensions are in $\mathrm{mm}$.

Table 1 Chemical composition, in mass fraction (\%), of the commercial Ti-6Al-4V alloy.

\begin{tabular}{cccccccc}
\hline $\mathrm{Ti}$ & $\mathrm{Al}$ & $\mathrm{V}$ & $\mathrm{Fe}$ & $\mathrm{C}$ & $\mathrm{N}$ & $\mathrm{H}$ & $\mathrm{O}$ \\
\hline Base & $5.5-6.8$ & $3.5-4.5$ & 0.3 & $\leq 0.08$ & $\leq 0.05$ & $\leq 0.015$ & $\leq 0.2$ \\
\hline
\end{tabular}

\subsection{Experimental technique}

An advantage of the $2 \mathrm{~B} / 2 \mathrm{SI}$ loading technique is that the traditional SHPB setup can be employed directly without significant modifications. In our experiments, the incident and transmitter bars had a length of $1200 \mathrm{~mm}$ and $1000 \mathrm{~mm}$, respectively; three striker bars of different length (viz. $380 \mathrm{~mm}$, $200 \mathrm{~mm}$, and $100 \mathrm{~mm}$ ) were used to obtain different incident pulse shape. All bars have a $19 \mathrm{~mm}$ diameter and are made of maraging steel. The strain gauges are located $460 \mathrm{~mm}$ away from the incident bar/specimen and transmitter bar/specimen interfaces. A specially designed high-strengthsteel mounting fixture (see Fig. 1(b)), to which the support end of the specimen will be inserted, is shown in Figs. $2 \mathrm{a}$ and $\mathrm{b}$. The two through slots, at one end, of the mounting fixture were designed 
to fit snugly with the support end of the specimen; they also serve to prevent transverse displacement of the test specimen. The other end of the mounting fixture has a hollow annular profile that attaches freely onto the head of the transmitter bar. With this fixture, bending of the specimen uncracked ligament is avoided.

A stress reversal Hopkinson technique (Nemat-Nasser et al., 1991) is adopted here to prevent specimen reloading. With this technique, the test specimen is always subjected to a single stress pulse for recovery and fractographic examination. An initial gap is introduced between the incident bar flange and the incident tube. When an entire compressive stress pulse propagates into the incident bar, the flange is brought into contact with one end of the incident tube (see Fig 3(a)), whilst the other end remains in contact with a reaction mass. The reflected tensile stress pulse from the incident bar/specimen boundary is transformed into tension again at the other end of the bar by the reaction mass. Thus, after the specimen is loaded by the first stress wave in compression, the crack maintains its morphology, since all subsequent pulses moving towards the specimen (in the incident bar) are tensile. The stress reversal system, and the assembly of the 2SF sample and fixture are shown in Figs. 2(a) and (b), respectively. A detailed description of the stress reversal technique was provided by Nemat-Nasser et al. (1991).

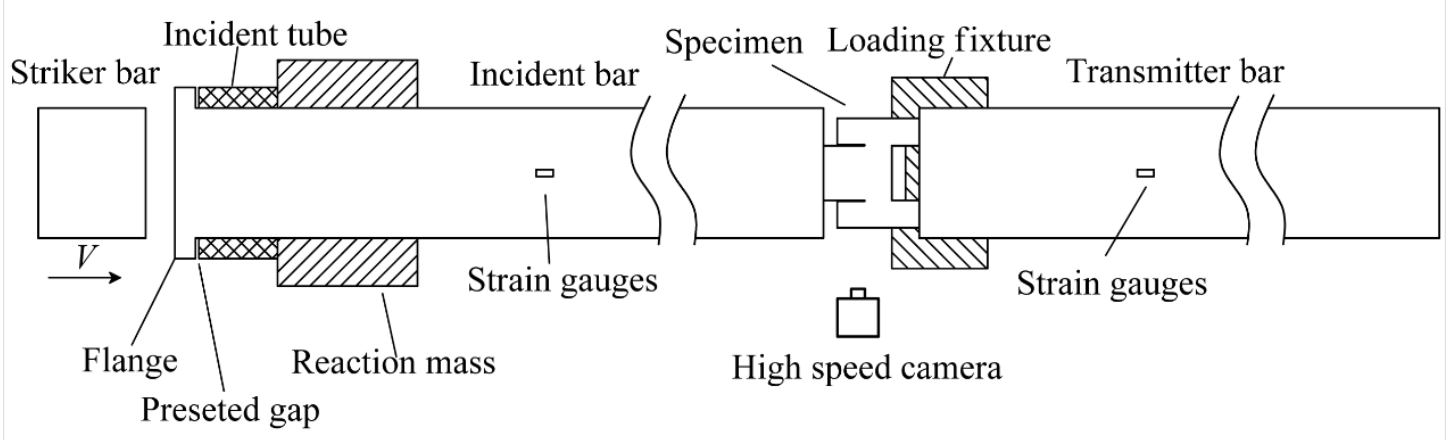

(a)

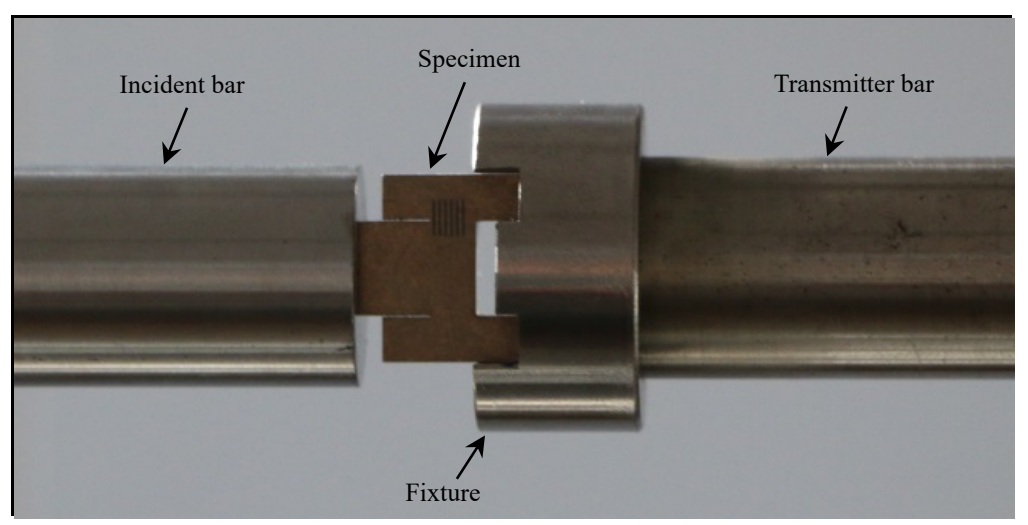

(b)

Figure 2. (a) Schematic and (b) details of the specimen arrangement in the $2 \mathrm{~B} / 2 \mathrm{SI}$ loading system.

Using the one-dimensional elastic stress wave theory, the forces and the displacements at the $\mathrm{bar} /$ specimen interfaces can be calculated from the strain gauge signals. The incident $\varepsilon_{\mathrm{i}}(t)$, reflected $\varepsilon_{\mathrm{r}}(t)$, and transmitted $\varepsilon_{\mathrm{t}}(t)$ strain waves are given by 


$$
\begin{aligned}
& \left\{\begin{array}{l}
F_{\text {input }}=A E\left(\varepsilon_{\mathrm{i}}(t)+\varepsilon_{\mathrm{r}}(t)\right) \\
F_{\text {output }}=A E \varepsilon_{\mathrm{t}}(t)
\end{array}\right. \\
& \left\{\begin{array}{l}
U_{\text {input }}=C_{0} \int_{0}^{t}\left(\varepsilon_{\mathrm{i}}(t)-\varepsilon_{\mathrm{r}}(t)\right) \mathrm{d} t \\
U_{\text {output }}=C_{0} \int_{0}^{t} \varepsilon_{\mathrm{t}}(t) \mathrm{d} t
\end{array}\right.
\end{aligned}
$$

where $F_{\text {input }}$ and $F_{\text {output }}$ are forces; $U_{\text {input }}$ and $U_{\text {output }}$ are displacements at the incident and transmitter bar ends, respectively; $A, E$ and $C_{0}$ are the cross-sectional area, Young's modulus and longitudinal wave speed of the bars, respectively.

The fracture initiation time is to be determined using the strain signals measured by the strain gauges. The strain gauges (BE120-05AA) used here were supplied by ZEMIC in Hanzhong, China. The dimensions of the strain gauges are $2.2 \mathrm{~mm} \times 1.5 \mathrm{~mm}$, and the area of the grid is $0.9 \mathrm{~mm} \times 0.5$ $\mathrm{mm}$. The strain gauge is mounted on the surface of the supporting block of the specimen. The center of the strain gauge is $2 \mathrm{~mm}$ away from the crack tip in both the vertical and the horizontal directions. The grids of the strain gauge are parallel to the loading direction. The location of the strain gauge is also schematically shown in Fig. 1(a).

\subsection{Experimental results}

A series of tests were performed at loading rates ranging between $1-50 \times 10^{6} \mathrm{MPa} \cdot \mathrm{m}^{1 / 2} \mathrm{~s}^{-1}$. By changing the profile of the incident stress pulses, the loading rate on the fracture can be controlled precisely. Fig. 3 shows typical stress/strain waves obtained from the Hopkinson bars and the test specimen, on the same time scale, where the loading rate $\dot{K}_{\mathrm{II}}=\mathrm{d} K_{\mathrm{II}} / \mathrm{d} t$ is $1.92 \times 10^{7} \mathrm{MPa} \cdot \mathrm{m}^{1 / 2} \mathrm{~s}^{-}$

${ }^{1}$. Note that here $\dot{K}_{\text {II }}$ is the transient loading rate at the fracture initiation time $t_{\text {f. }}$ Negative voltage indicates that the stress wave is compressive; whilst its positive counterpart indicates tension. Fig. 3 shows that a compressive stress pulse is first generated, and this propagates along the incident bar towards the specimen, which is reflected as a tensile stress pulse from the incident bar/specimen interface. Parts of the original incident stress pulse is transmitted through the specimen into the transmitter bar in compression. It is worth highlighting that the duration of the transmitted stress pulse is much shorter than its incident counterpart, implying that the specimen had failed immediately after the first loading wave propagates through it, and that subsequent incident pulses were completely reflected back into the incident bar. This is easily verified since the maximum voltage of all subsequent reflected stress, pulse following the initial one, are similar apart from a sign reversal. Notice that the majority of the tensile wave is reflected as tension again by the mass block, following a small residue of the reflected stress wave in compression. The sharp peak in the signal corresponding to fracture initiation in Fig. 3 indicates rapid failure of the specimen during the impact loading. This peak corresponds to a sudden release of the accumulated strain energy in the specimen as the pre-cracks start to extend. 


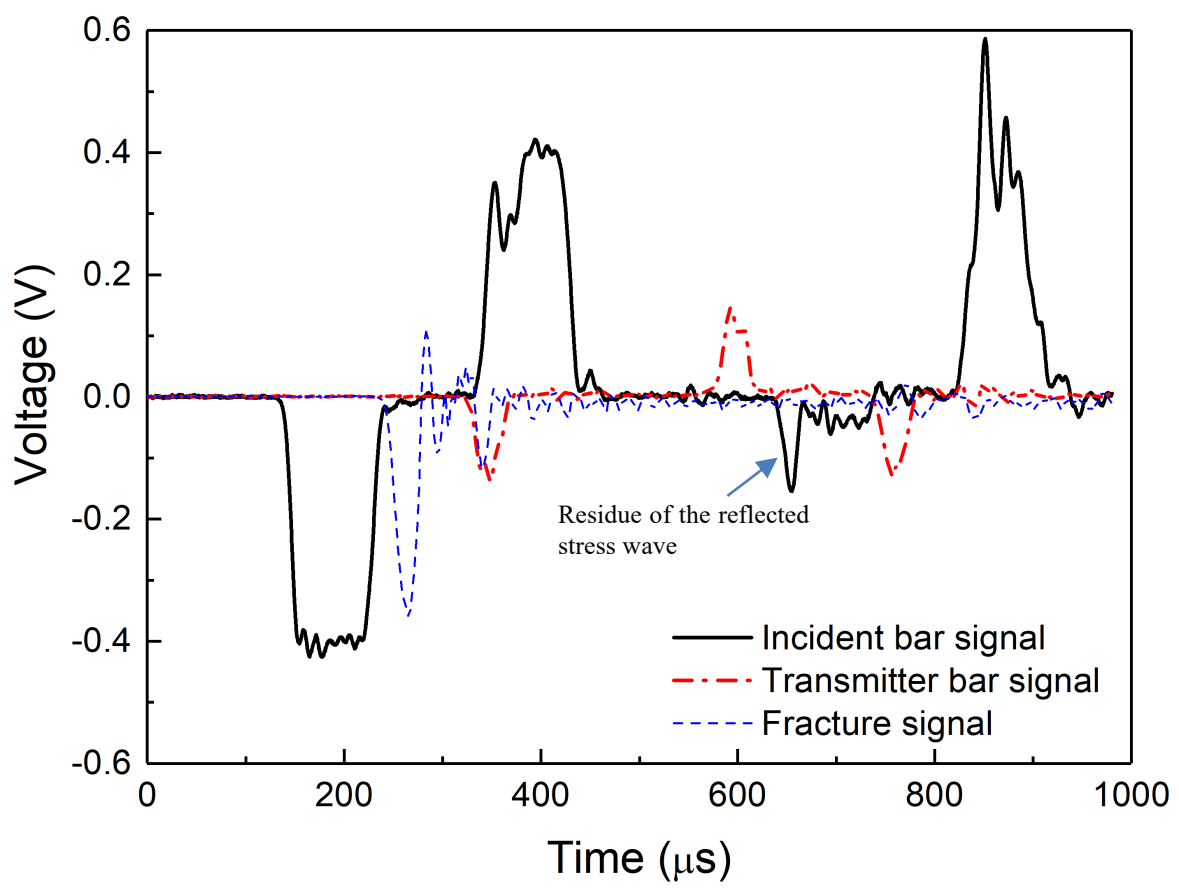

Figure 3. Typical strain gauge signals from the pressure bars and the specimen at a loading rate of $1.92 \times 10^{7} \mathrm{MPa}$ $\cdot \mathrm{m}^{1 / 2} \mathrm{~s}^{-1}$.

The first incident, reflected and transmitted strain signals measured in the same test were plotted in Fig. 4; and, its corresponding displacement and force histories at the incident bar/specimen interface, obtained using Eqs. (1) and (2), in Fig. 5. Due to stress waves reflection at the interface, large oscillations occur in the temporal history of the force pulse; however, the incident bar/specimen interface force does not reduce to zero until $\sim 54 \mu$ s when the specimen has completely fractured. This implies that the specimen and bar remain in constant contact throughout the loading process. By contrast, the corresponding displacement at the incident bar/specimen interface increases, almost, linearly between $10-90 \mu \mathrm{s}$, and remains relatively constant beyond $106 \mu \mathrm{s}$ (corresponding to the end of the first loading wave in the incident bar).

To check for force equilibrium in the specimen, the input $\left(F_{\text {input }}\right)$ and output $\left(F_{\text {output }}\right)$ forces are plotted in Fig. 6 . Notice that both $F_{\text {input }}$ and $F_{\text {output }}$ have a largely similar increasing trend, with the $F_{\text {output }}$ signal slightly lower than $F_{\text {input. }}$ Beyond $20 \mu$ s, the curves separate due to oscillations in $F_{\text {input. }}$ At $\sim 54 \mu$ s, corresponding to complete specimen fracture, both forces reduce to zero. Fig. 6 shows that, during the loading process, force equilibrium is not achieved in the specimen. Therefore, in the determination of the DSIFs, the assumption of force equilibrium cannot be used here. In this work, the DSIF and DFT of the specimen were determined by a combined experimental-numerical method (Xu and Li, 2012; Xu et al., 2006, 2012), where force equilibrium is not required. A high-fidelity three-dimensional (3D) FEA will be performed to obtain the displacements corresponding to the crack tip field; and a displacement method, to be introduced in the next section, will be used to determine the time history of the DSIF at the crack tip. 


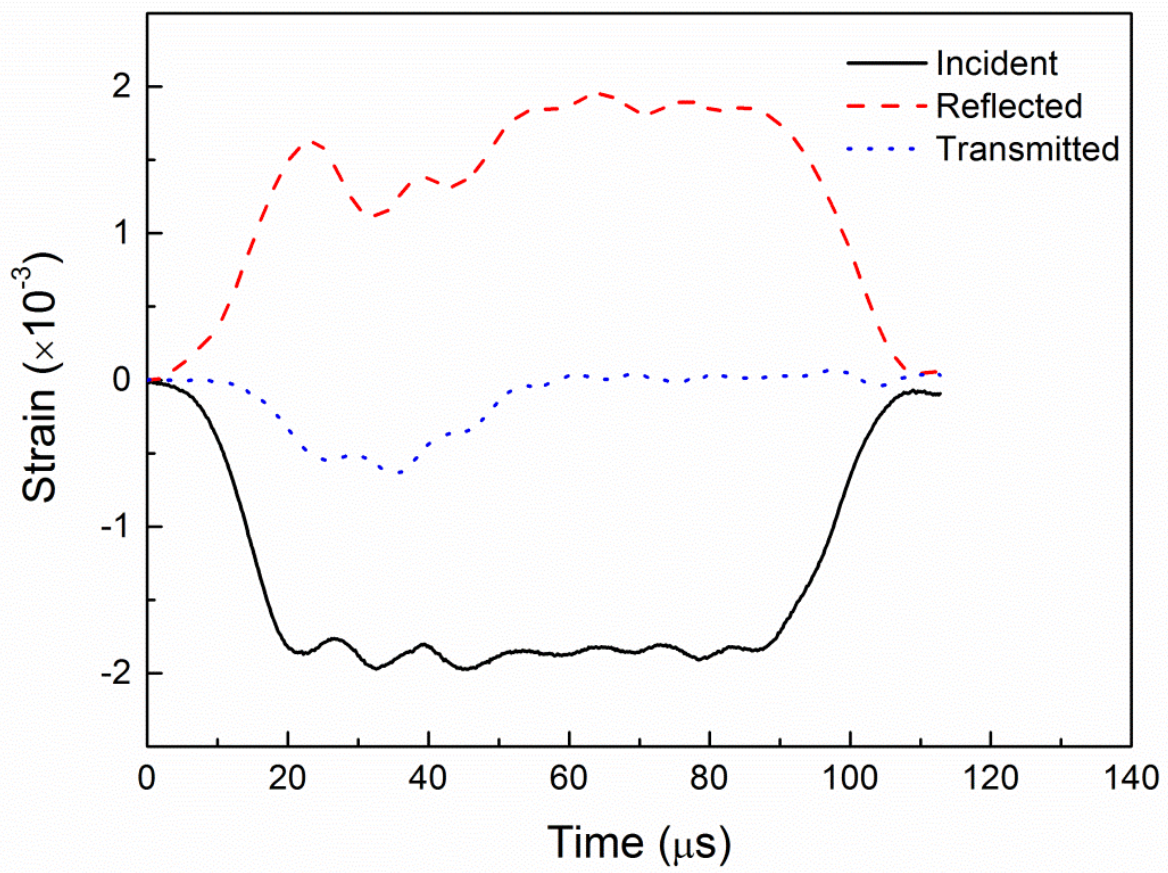

Figure 4. The first incident, reflected and transmitted strain pulses measured at a loading rate of $1.92 \times 10^{7} \mathrm{MPa}$. $\mathrm{m}^{1 / 2} \mathrm{~s}^{-1}$.

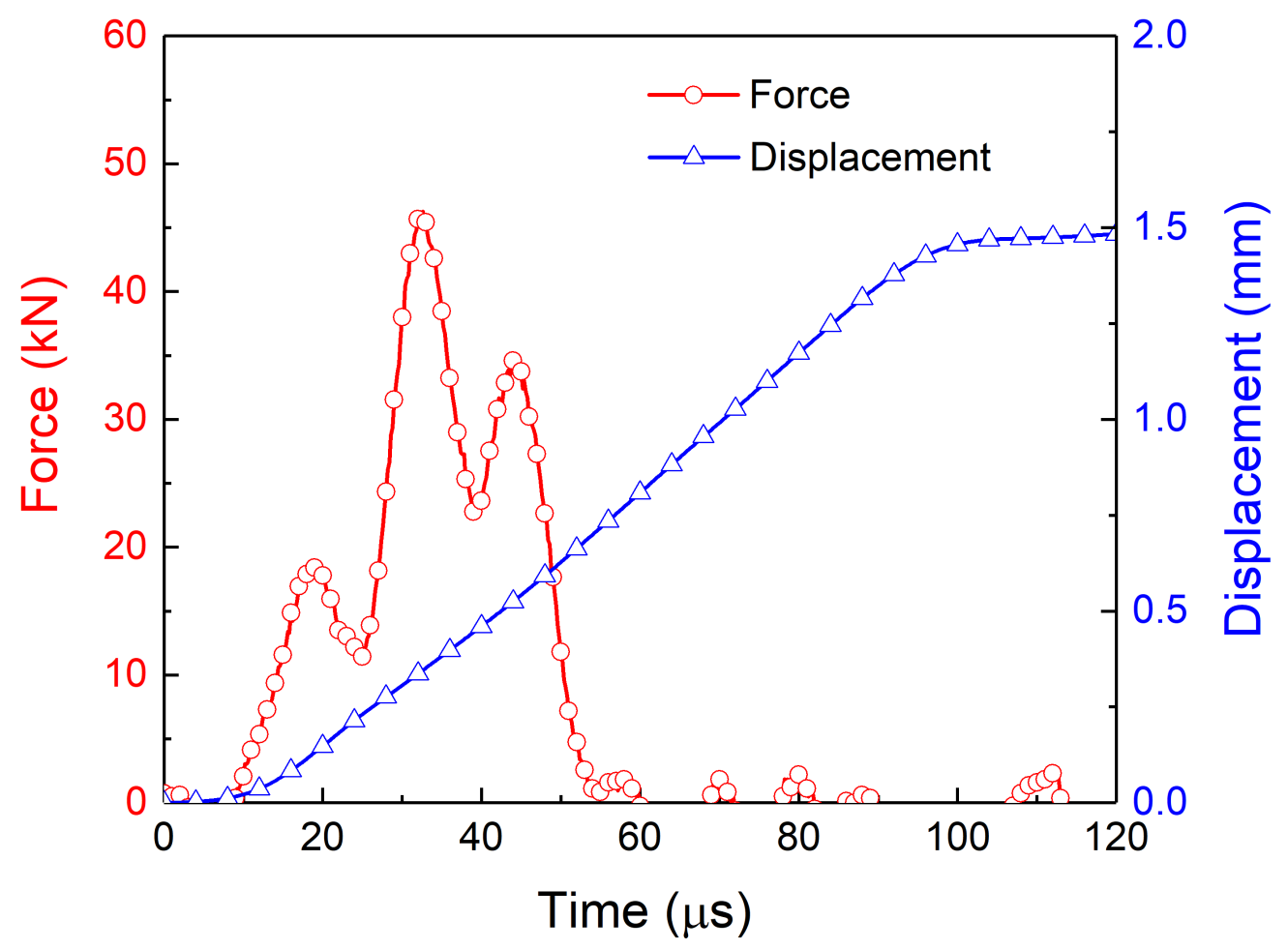

Figure 5. Temporal displacement and force histories, at the incident bar/specimen interface, calculated using Eqs. (1) and (2). 


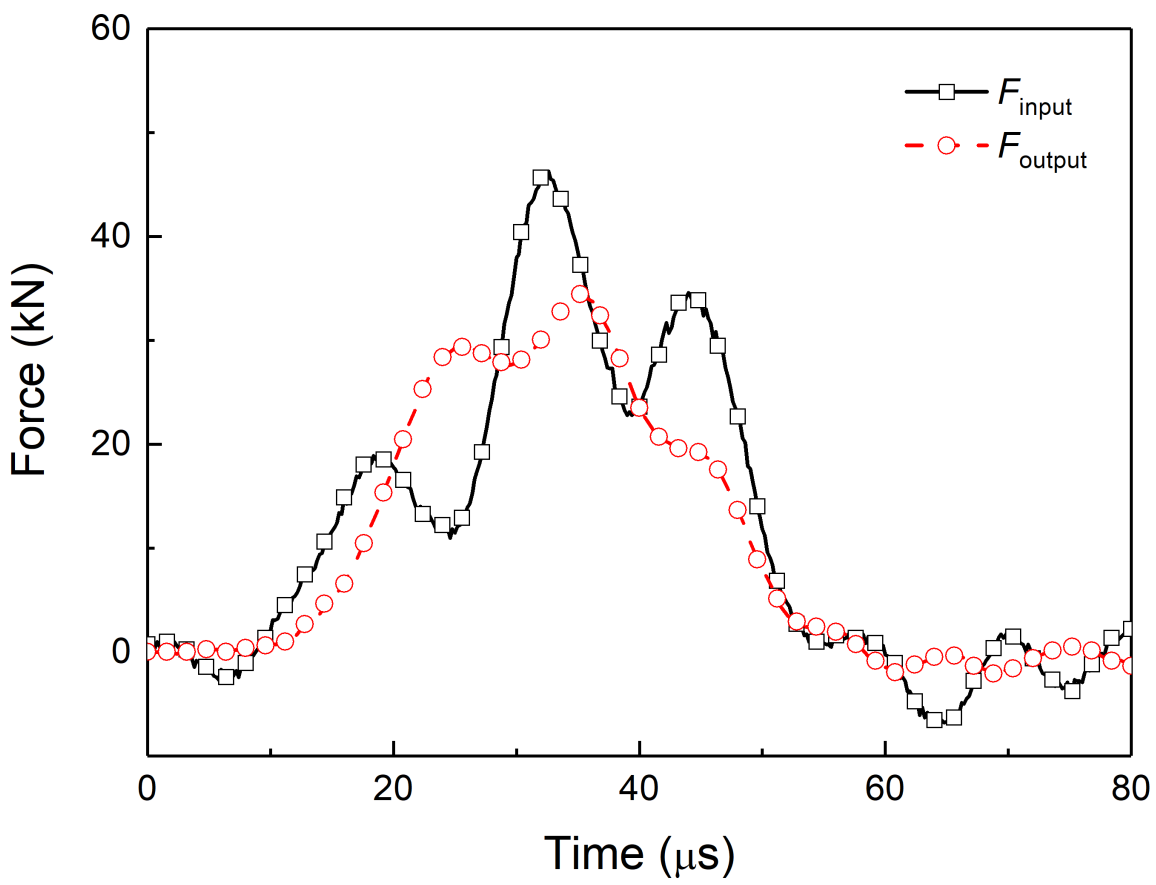

Figure 6. Comparison of forces measured at the incident bar/specimen and transmitter bar/specimen interfaces.

A high-speed camera was used to record the motion of the crack tip at 124000 fps (frames per second). Fig. 7 shows the cracks extension at a loading rate of $1.92 \times 10^{7} \mathrm{MPa} \cdot \mathrm{m}^{1 / 2} \mathrm{~s}^{-1}$. To better visualise the relative displacement of the extended fracture surfaces, six grid lines were inscribed across one of the uncracked ligament at equal intervals of $0.5 \mathrm{~mm}$. For the initial $16.1 \mu \mathrm{s}$, plastic deformation is minimal in the ligament since all the stripes remain vertically aligned. Extension of both crack tips were observed from $24.2 \mu$ s - they are inclined/deflected towards the center of the specimen. Concurrently, two bright lines were observed to emanate from each crack tip -this is indicative of the localization of plastic deformation in the ligaments. However, no obvious shear banding was observed yet, although the crack surfaces had come into contact due to crack closure. Between $32.2 \mu$ s to $40.3 \mu$ s, the cracks extend continuously, while shear banding starts to develop in the ligaments. At $32.2 \mu$ s, obvious slippage was observed for the first 4 grid lines along the bright shear zones (blue arrows). This suggests that large plastic deformation was localized into shear zones where ASB took place. From $48.4 \mu$ s, the lower crack tip comes into contact and interacts with the shear bands; the upper crack tip stops growing and a new crack (indicated by a blue arrow) appears to originate from the shear band. In this way, further propagation of the original inclined/deflected cracks towards the center of the specimen is inhibited. At $56.4 \mu \mathrm{s}$, a new fracture in the upper ligament (blue arrow) - this is now clearly visible - continues to grow and intersects with the previously formed inclined crack surface. From $32.2 \mu \mathrm{s}$ to $56.4 \mu \mathrm{s}$, the pre-crack surfaces open gradually. It was observed that under dynamic shear loading, both DSF and ASB develops simultaneously, and interacts with each other, in the ligament. At the beginning, crack initiation occurs without interference from the ASB. It grows at an inclined angle towards the center of the specimen. Propagation of fracture in the ligament of the specimen are governed by interactions between the DSF and ASB, where the DSF either coalesces with the ASB or is interrupted by the 
development of a new fracture within the ASB.
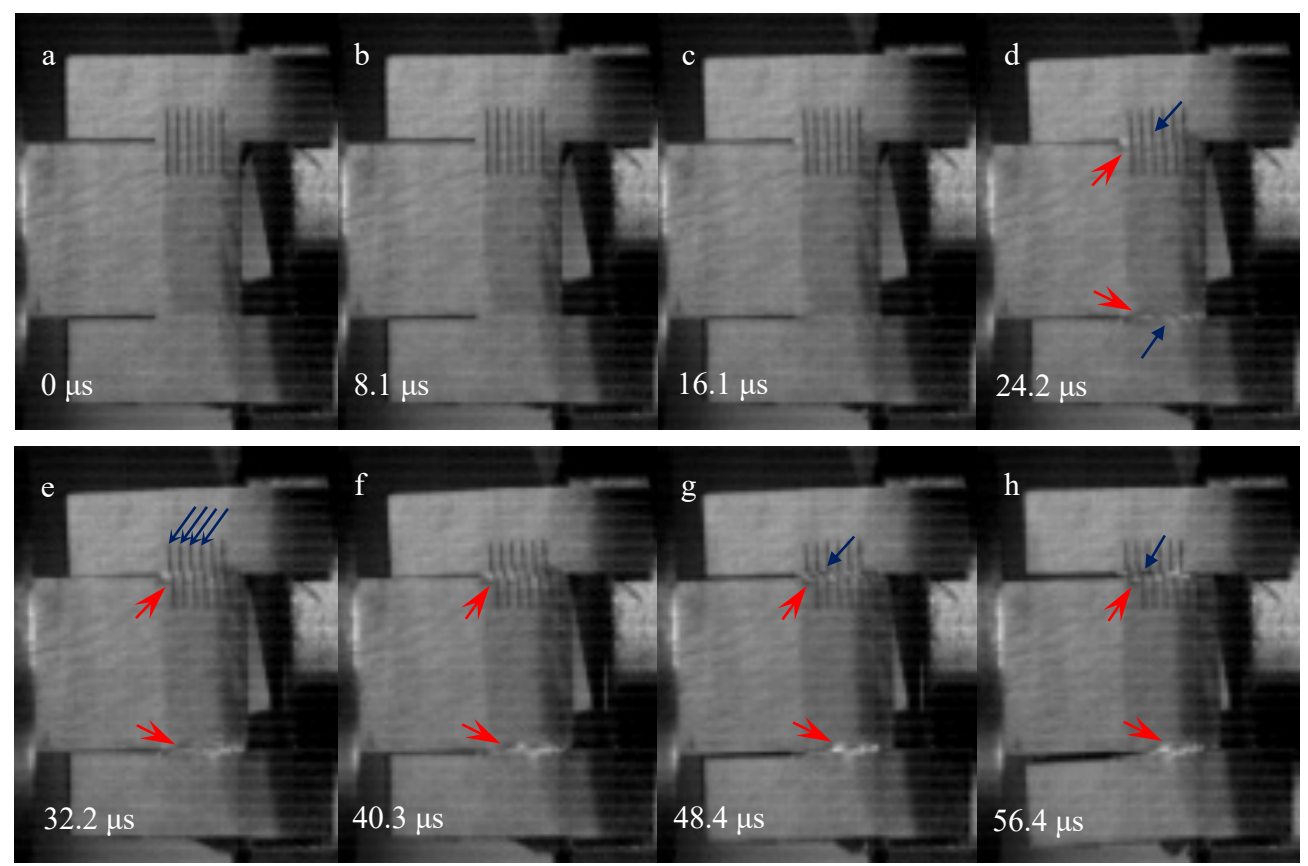

Figure 7. Extension of the crack tips and its interaction with ASB at $1.92 \times 10^{7} \mathrm{MPa} \cdot \mathrm{m}^{1 / 2} \mathrm{~s}^{-1}$. Extended crack tips are indicated by red arrows and blue arrows indicate the bright plastic zones. formed across the ligament.

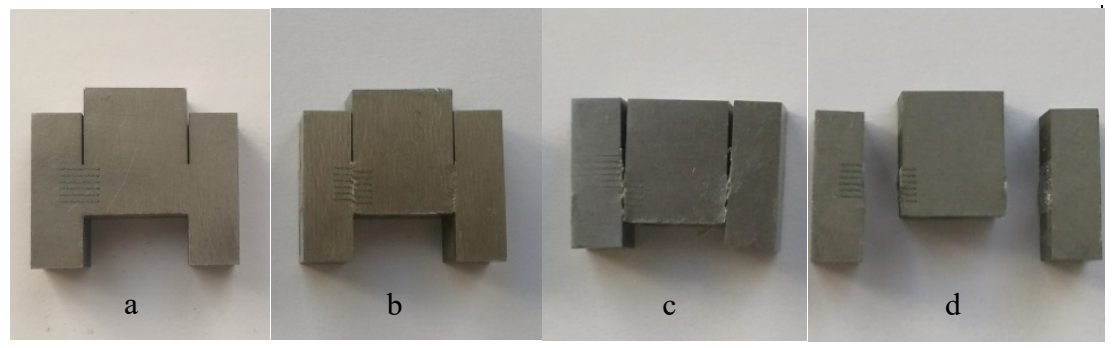

Figure 8. (a) Undeformed specimen; and, post-test specimens at loading rates of (b) $1.84 \times 10^{6} \mathrm{MPa} \cdot \mathrm{m}^{1 / 2} \mathrm{~s}^{-1}$ (c) 3.37 $\times 10^{7} \mathrm{MPa} \cdot \mathrm{m}^{1 / 2} \mathrm{~s}^{-1}$ and (d) $4.74 \times 10^{7} \mathrm{MPa} \cdot \mathrm{m}^{1 / 2} \mathrm{~s}^{-1}$.

Fig. 8 shows undeformed and post-test specimens at various loading rates. At a loading rate of $1.84 \times 10^{6} \mathrm{MPa} \cdot \mathrm{m}^{1 / 2} \mathrm{~s}^{-1}$, crack extension was arrested at some point within the ligament. At $3.37 \times$ $10^{7} \mathrm{MPa} \cdot \mathrm{m}^{1 / 2} \mathrm{~s}^{-1}$, the fractured surfaces were fused together as the melted material rapidly cooled; at $4.74 \times 10^{7} \mathrm{MPa} \cdot \mathrm{m}^{1 / 2} \mathrm{~s}^{-1}$ (Fig. 8d), the specimen had entirely fractured. Detailed fracture morphologies of the cracked specimens will be presented in section 4 .

\section{Determination of mode II DFT}

\subsection{Theoretical background}

Under dynamic loading, the crack tip stress and displacement fields, expressed in polar coordinates $r$ and $\theta$, see Fig. 9, are given by (Chen and Sih, 1977) 


$$
\begin{aligned}
& u(r, \theta, t)=\frac{K_{\mathrm{I}}(t)}{4 G} \sqrt{\frac{r}{2 \pi}}\left[(2 k-1) \cos \frac{\theta}{2}-\cos \frac{3 \theta}{2}\right]+\frac{K_{\mathrm{II}}(t)}{4 G} \sqrt{\frac{r}{2 \pi}}\left[(2 k+3) \sin \frac{\theta}{2}+\sin \frac{3 \theta}{2}\right] \\
& v(r, \theta, t)=\frac{K_{\mathrm{I}}(t)}{4 G} \sqrt{\frac{r}{2 \pi}}\left[(2 k+1) \sin \frac{\theta}{2}-\sin \frac{3 \theta}{2}\right]-\frac{K_{\mathrm{II}}(t)}{4 G} \sqrt{\frac{r}{2 \pi}}\left[(2 k-2) \cos \frac{\theta}{2}+\cos \frac{3 \theta}{2}\right] \\
& w(r, \theta, t)=0 \quad \text { (plane strain) } \\
& w(r, \theta, t)=-\frac{\mu}{E} \int\left[\sigma_{\mathrm{x}}(r, \theta, t)+\sigma_{\mathrm{y}}(r, \theta, t)\right] \mathrm{d} z \quad \text { (plane stress) }
\end{aligned}
$$

where $\mu$ is Poisson's ratio, $G$ is shear modulus, $r$ is the distance to the crack tip, and

$$
k= \begin{cases}3-4 \mu & \text { (plane strain) } \\ \frac{3-\mu}{1+\mu} & \text { (plane stress) }\end{cases}
$$

If the transverse and longitudinal displacements ( $u$ and $v$, respectively) are known for nodal points along a radial line from the crack tip, then the temporal histories of the modes I and II DSIF, given respectively by $K_{\mathrm{I}}(t)$ and $K_{\mathrm{II}}(t)$, can be determined using the following equations:

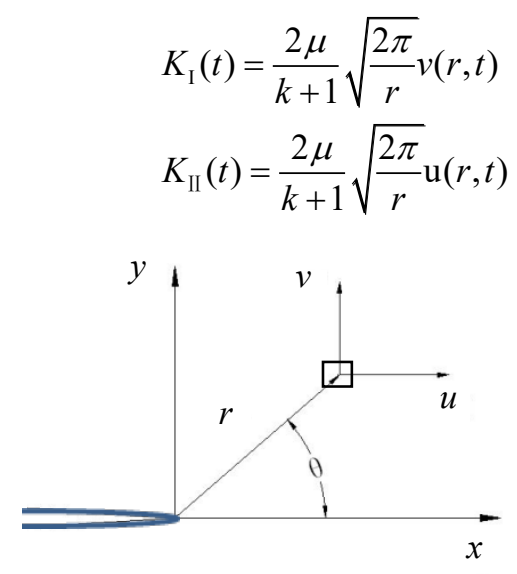

Figure 9. Coordinate system at the crack tip.

\subsection{Numerical simulation}

To determine the DSIF, 3D FE simulations were performed using ABAQUS/Explicit to obtain the displacement field at the crack tips in each test. Details of the FE model and simulation results for the test conducted at $1.92 \times 10^{7} \mathrm{MPa} \cdot \mathrm{m}^{1 / 2} \mathrm{~s}^{-1}$ are presented here. The pressure (incident and transmitter) bars, test specimen, and the fixture were modelled. Both the pressure bars and fixture were modelled as elastic bodies. A Johnson-Cook (JC) constitutive model by Seo et al. (2005) is adopted here to simulate the adiabatic shear condition and the thermo-viscoplastic behavior at the crack tip; however, material failure was not considered in our simulations. To check the validity of the JC model, dynamic compressions, using the SHPB technique, were performed on the Ti-6Al$4 \mathrm{~V}$ alloy at different temperatures $(298 \mathrm{~K}$ to $673 \mathrm{~K})$ and strain rates $\left(1500 \mathrm{~s}^{-1}\right.$ to $\left.6500 \mathrm{~s}^{-1}\right)$. Comparison between the experimental results and model predictions in Fig. 10 shows that the JC model gives a sufficiently accurate description of the plastic behavior of the Ti-6Al-4V alloy. It must be emphasized that an adiabatic temperature rise was assumed for the experimental data. The material properties for the pressure bars, specimen and fixture are listed in Table 2. In the JC model, the equivalent stress $\sigma$ is expressed by 


$$
\sigma=\left(A+B \varepsilon^{n}\right)\left(1+C \ln \dot{\varepsilon}^{*}\right)\left(1-T^{* m}\right)
$$

where $\varepsilon$ is the equivalent plastic strain; $\dot{\varepsilon}^{*}=\dot{\varepsilon} / \dot{\varepsilon}_{0}$ is the dimensionless plastic strain rate (with $\dot{\varepsilon}_{0}$ $\left.=1 \mathrm{~s}^{-1}\right)$; and, $T^{*}=\left(T-T_{\mathrm{r}}\right) /\left(T_{\mathrm{m}}-T_{\mathrm{r}}\right)$ is the homologous temperature. Here $T$ is the absolute temperature, $T_{\mathrm{r}}(=298 \mathrm{~K})$ is the reference temperature, and $T_{\mathrm{m}}(=1941 \mathrm{~K})$ is the melting temperature of the material. The material constants are tabulated in Table 3.

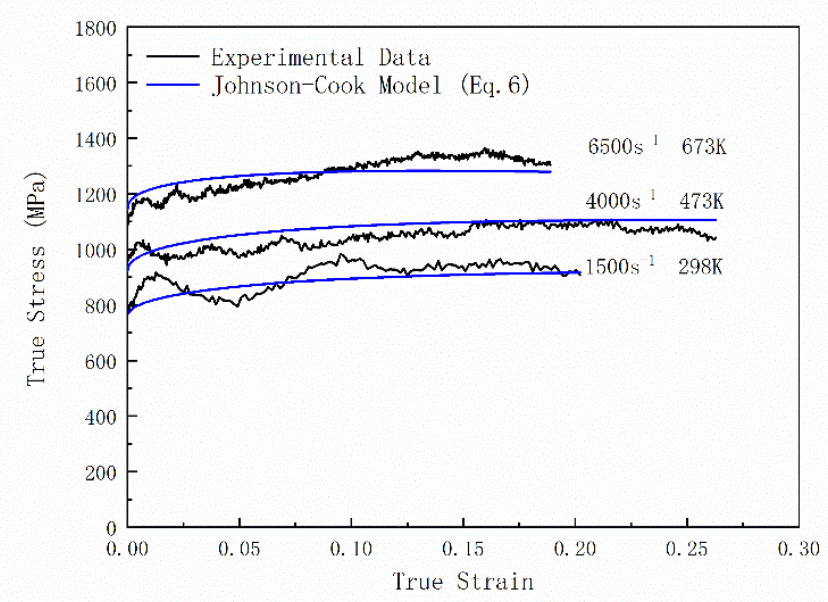

Figure 10. Comparison between test results and the corresponding JC model prediction.

The FE model simulate an identical set-up, see Fig. 11(a), to that in the experiment as shown in Fig. 2. The incident wave, that was measured experimentally, was applied to the end of the incident bar as a pressure input. Fig. 12 shows the incident pressure pulse applied to the incident bar to simulate a loading rate of $1.92 \times 10^{7} \mathrm{MPa} \cdot \mathrm{m}^{1 / 2} \mathrm{~s}^{-1}$. The contact at the interfaces between specimen, fixture and pressure bars is modelled as "hard" contact. Sliding friction between the different parts and between the pre-made crack faces are neglected. The 8-node linear brick, reduced integration elements (C3D8R) were used to mesh the bars and fixture. To refine the elements at the crack tips, three different types of elements were used in the specimen: a 4-node thermally coupled tetrahedron elements (C3D4T) were used for the majority of the test specimen and the 8-node thermally coupled brick elements (C3D8T) were used in the vicinity of the two crack tips. The 6-node thermally coupled triangular prism elements (C3D6T) were used for the transition between the aforementioned elements. Fig. 11(b) shows the mesh of a typical test specimen. The initial temperature of the specimen was set to $298 \mathrm{~K}$ and the Taylor-Quinney coefficient is set at 0.4 (Rittel et al., 2017). To increase the precision of computation, elements in the vicinity of the crack tip are refined so that the smallest element used is about $20 \mu \mathrm{m}$. With further refinement, very little changes were observed in the predicted displacement fields. The FE model of the test specimen in Fig. 11 has approximately 171000 elements in total. 


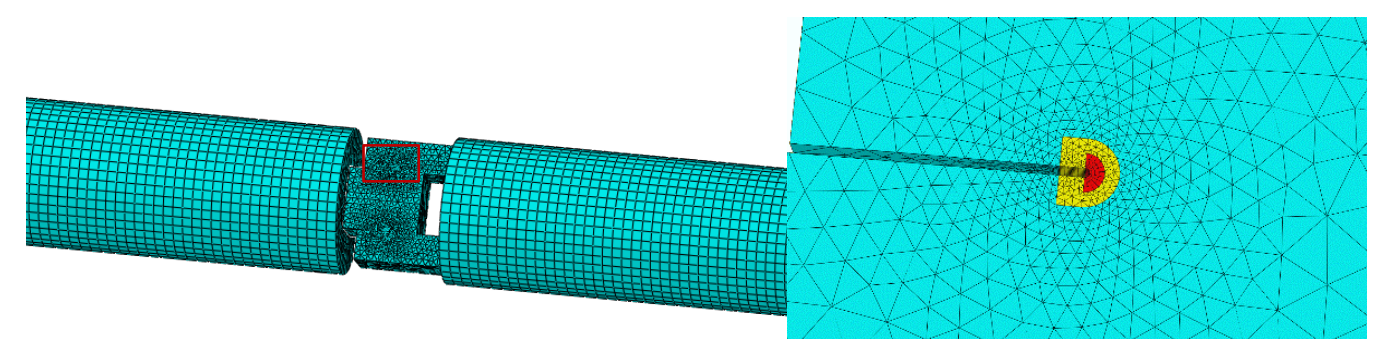

(a)

(b)

Figure 11. (a) The FE model of the experimental set-up and (b) the mesh in the vicinity of the crack tip (Red for C3D8T, yellow for C3D6T, and blue for C3D4T).

Table 2 Material parameters used in the FE model

\begin{tabular}{ccccccc}
\hline Part & Material & $\begin{array}{c}\text { Density, } \\
\rho \\
\left(\mathrm{g} / \mathrm{mm}^{3}\right)\end{array}$ & $\begin{array}{c}\text { Young's } \\
\text { Modulus, } \\
E(\mathrm{GPa})\end{array}$ & $\begin{array}{c}\text { Poisson's } \\
\text { Ratio, } \mu\end{array}$ & $\begin{array}{c}\text { Thermal } \\
\text { conductivity } \\
(\mathrm{W} /(\mathrm{m} \cdot \mathrm{K}))\end{array}$ & $\begin{array}{c}\text { Specific } \\
\text { heat } \\
(\mathrm{J} /(\mathrm{kg} \cdot \mathrm{K}))\end{array}$ \\
\hline Specimen & Ti-6Al-4V & 4.43 & 114 & 0.33 & 6.7 & 470 \\
SHPB Bars & $18 \mathrm{Ni}$ & 8.0 & 190 & 0.3 & - & - \\
Fixture & Steel & 7.8 & 210 & 0.3 & & \\
\hline
\end{tabular}

Table 3 Material constants for the JC model (Seo et al., 2005)

\begin{tabular}{ccccc}
\hline$A(\mathrm{MPa})$ & $B(\mathrm{MPa})$ & $n$ & $C$ & $m$ \\
\hline 997.9 & 653.1 & 0.45 & 0.0198 & 0.7 \\
\hline
\end{tabular}

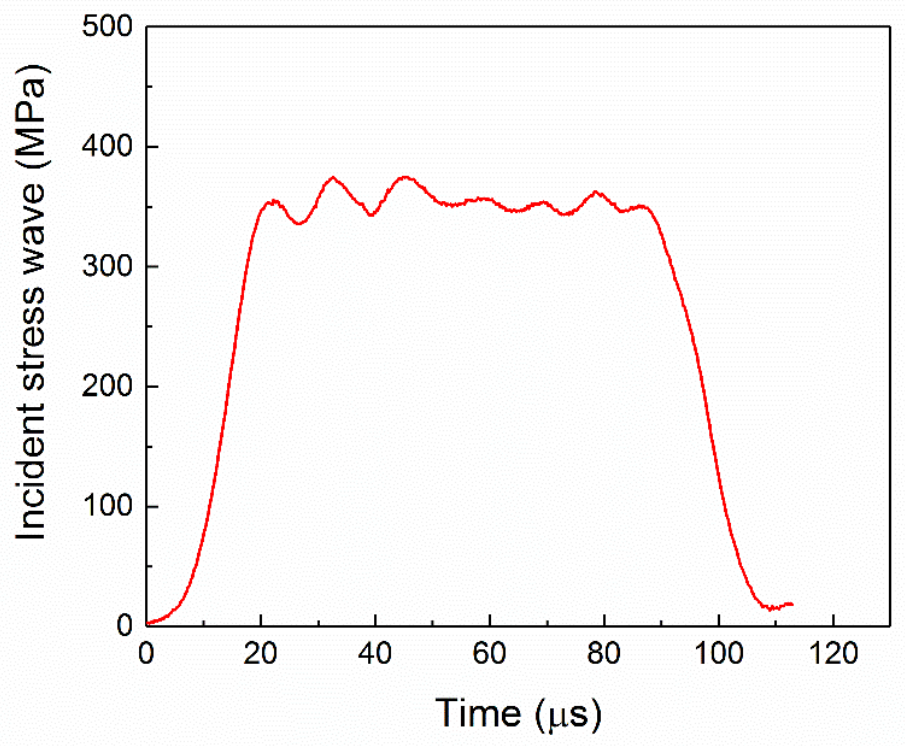

Figure 12. Pressure loading applied to the incident bar in the FE model to simulate a loading rate of $1.92 \times 10^{7}$

$$
\mathrm{MPa} \cdot \mathrm{m}^{1 / 2} \mathrm{~s}^{-1} \text {. }
$$

The reflected and transmitted stress waves predicted by FE are compared to its experimental counterpart in Fig. 13. There is good general agreement between predictions and experiment before 
$25 \mu$ s (transmitted pulse) and $20 \mu$ s (reflected pulse). Since our FE model did not consider material failure, the prediction deviates from those measured in the experiment following the initiation of fracture which occurs around $25 \mu \mathrm{s}$. Notwithstanding, the results show that prior to the initiation of cracking, the FE simulation predicts well the test data.

To determine the fracture initiation time precisely, simulated and experimental strain signals were extracted from the specimen and compared in Fig. 14. The two curves initially overlap but starts to deviate from approximately $24 \mu \mathrm{s}$, with the predicted strain being higher than its experimental counterpart post bifurcation. In general, the time from when the two aforementioned curves bifurcate compares well with that shown in Fig. 9 when crack extension was observed from $24.2 \mu$ s. It is also worth highlighting that localization of plastic deformation also occurs at around the same time in the ligament. Extension of the crack tip and the formation of shear localization will result in the release of some stored strain energy; hence, the measured strain in the specimen is, in general, lower than that predicted by FE. Based on the above, we selected $24 \mu$ s as the starting time beyond which fracture initiates in the specimen. The results showed that the experimental results are consistent with the simulations in Fig. 14.

Fig. 7 showed that initially inclined crack was prevented from further extension by its interaction with the ASB, suggesting that the material did not lose its load carrying capacity immediately. Therefore, in Fig. 14 the measured fracture signal continues to rise beyond $24 \mu$ s, but at a smaller gradient before it decreases dramatically beyond approximately $32 \mu \mathrm{s}$. In Fig. 7, the slip in the stripes showed that large plastic deformation is localized in the shear band at $32.2 \mu \mathrm{s}$. Both the experimental observation and numerical simulations indicate that ASBs had formed in the ligament at this point in time.

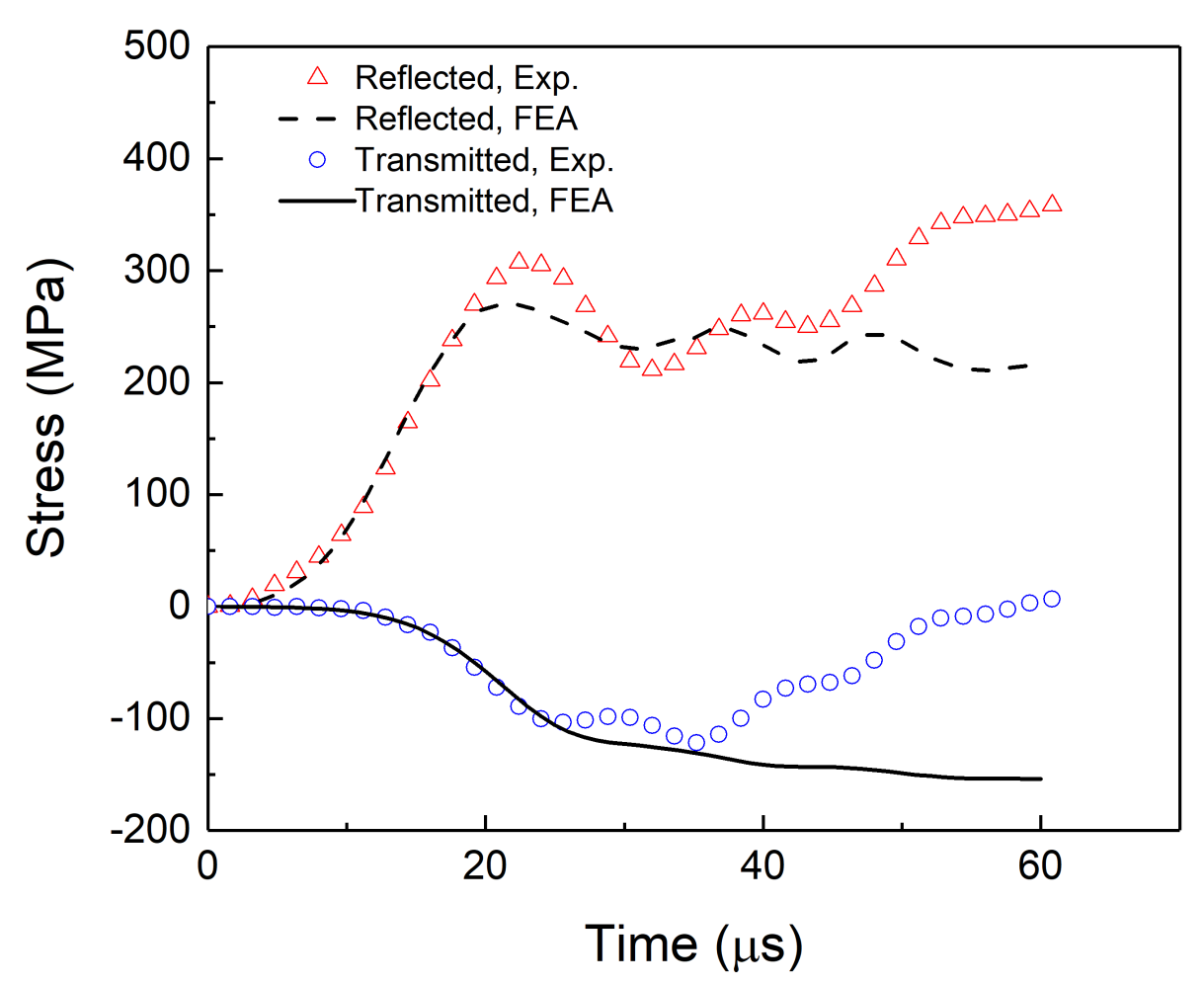

Figure 13. Comparison between the simulated and the experimental stress pulses. 


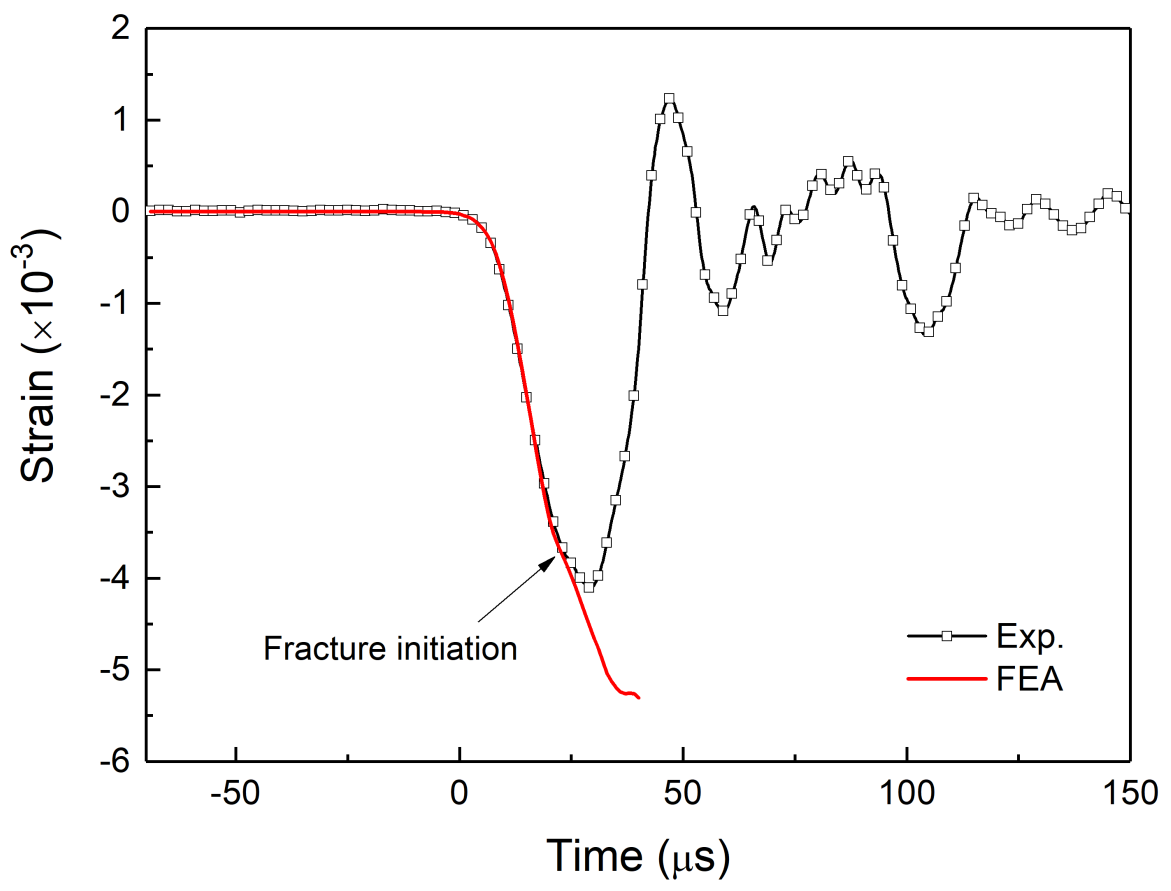

Figure 14. Comparison between the simulated and the experimental strain signals for the specimen.

The FE results (von Mises stress contours) are shown together with its corresponding high-speed video images at different time points in Fig. 15. It is observed that the FE model is able to predict well the deformation process. The predicted deformation of the inscribed lines are highlighted by the dotted red lines in the simulation results, and they matched well with the experiments. During the loading process, large stress gradients were generated around the crack tips, and plastic deformation develops from the crack tip (Figs. 15a and b) towards the ligament of the specimen with time (Figs. 15c). By contrast, the rest of the loading and supporting sections in the specimen remain predominantly elastic. It is observed in Figs. 15b and c that the highest stress emerges in the location that is closer to the center of the specimen, which explains why the crack tip initially extends towards the center of the specimen (in Figs. $7 \mathrm{~d}$ and e). Since cracks extension occurs from approximately $24 \mu \mathrm{s}$, the FE predictions are valid before $24.2 \mu \mathrm{s}$. It is worth highlighting that closure of the crack surfaces is also successfully captured in the simulations.

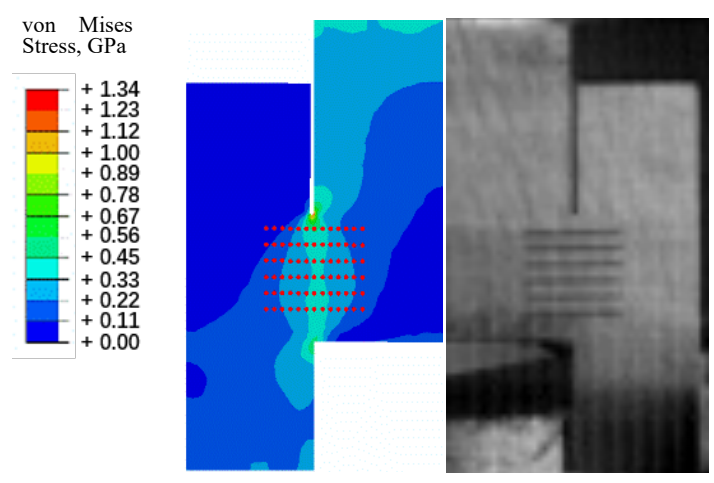

(a)

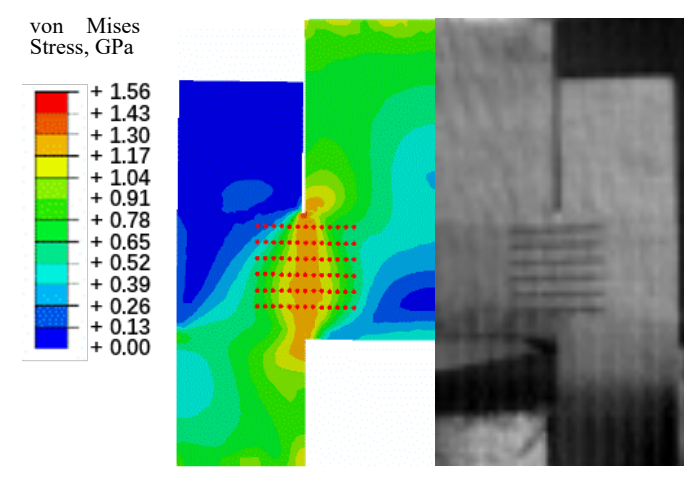

(b) 


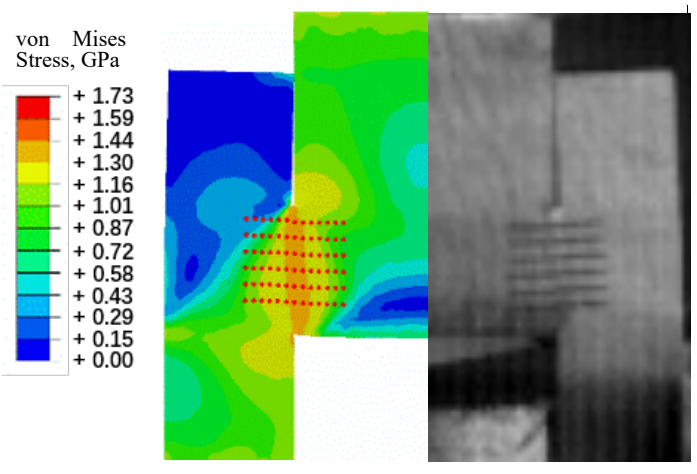

(c)

Figure 15. Comparison between the FEA predictions and experiments at (a) $16.1 \mu \mathrm{s}$, (b) $20.1 \mu \mathrm{s}$, and (c) $24.2 \mu \mathrm{s}$.

To determine the strain rate distribution in the vicinity of the crack tip, 14 points were selected along the outer crack face and the ligament as indicated in Fig 16(a). The strain rate along the loading direction are given in Fig 16(b) for those locations. A maximum strain rate of $6091 \mathrm{~s}^{-1}$ is predicted for the top of the crack tip (location 10). Beyond that point, the strain rate decreases rapidly for the upper and lower locations. Simulations reveal that the largest deformation occurs at the center of the crack tip, and this is also where the crack starts to extend. Since the JC model can accurately describe the material behavior up to $6500 \mathrm{~s}^{-1}$ (Fig. 10), the dynamic material response in the vicinity of the crack tip is reliably simulated using this model.

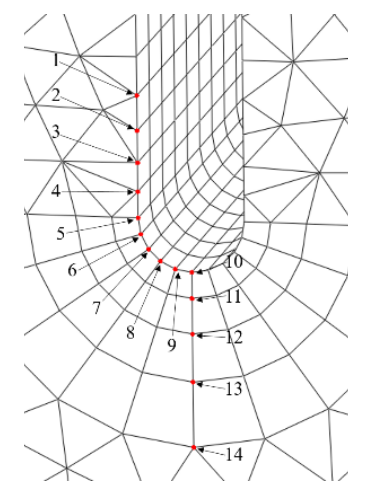

(a)

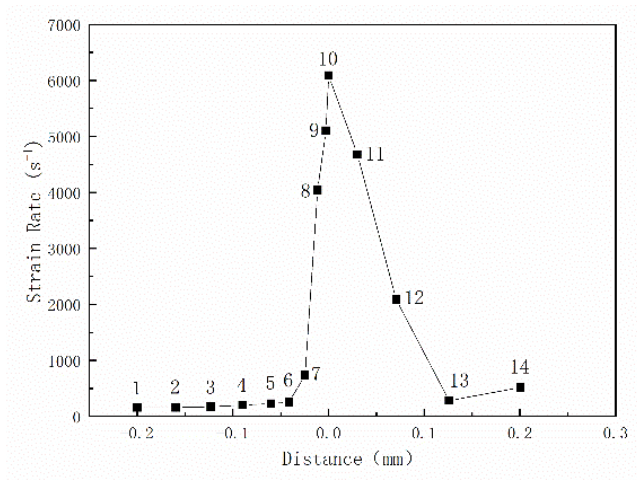

(b)

Fig. 16 Strain rate distribution in the vicinity of the crack tip at the fracture initiation time: (a) the location of the selected points and (b) corresponding strain rate at those points.

\subsection{Mode II DFT}

The mode I and mode II DSIFs, viz. $K_{\mathrm{I}}$ and $K_{\mathrm{II}}$, can be calculated by the transverse and longitudinal displacements at fracture surfaces $(\theta=\pi)$. Note that the displacements are functions of the radial distance $r$ and time $t$ in Eq. (5). At a loading rate of $1.92 \times 10^{7} \mathrm{MPa} \cdot \mathrm{m}^{1 / 2} \mathrm{~s}^{-1}$, the mode II DSIFs are calculated for various locations along the fracture surface and at different loading time. Ignoring the data points in the vicinity of the crack tip where large plastic deformation occurred, the values of $K_{\text {II }}$ can be obtained by a straightforward linear extrapolation method (Xu and $\mathrm{Li}, 2011$, 2012). The temporal variation of $K_{\mathrm{II}}(t)$ is shown in Fig. 17. For comparison, its $K_{\mathrm{I}}(t)$ counterpart is also plotted in the same graph. Notice that the $K_{\mathrm{I}}(t)$ curve dips below zero which implies that the crack surfaces tend to close during the loading process - this gives rise to a negative relative displacement between the crack surfaces. This phenomenon was previously identified in both the experiments and the numerical simulation (see Fig. 15). This result is also consistent with the work of Lee and Freund (1990) where a negative mode I DSIF component was also found due to the gap 
between the crack faces.

Figure 17 shows that, unlike $K_{\mathrm{I}}(t), K_{\mathrm{II}}(t)$ increases rapidly with the loading time. For the bulk of the loading duration the values of $K_{\mathrm{I}}(t)$ are much lower than $K_{\mathrm{II}}(t)$, with the latter playing a dominant role in the failure process. It must be emphasized that $K_{\mathrm{I}}(t)$ are negative throughout - this is due to closure of the crack surfaces during loading. This implies that the component of $K_{\mathrm{I}}(t)$ cannot induce the initiation of failure in an opening mode. Hence, it is reasonable to assume that the contributions by the mode I DSIF on the fracture behavior of the specimen is negligibly small.

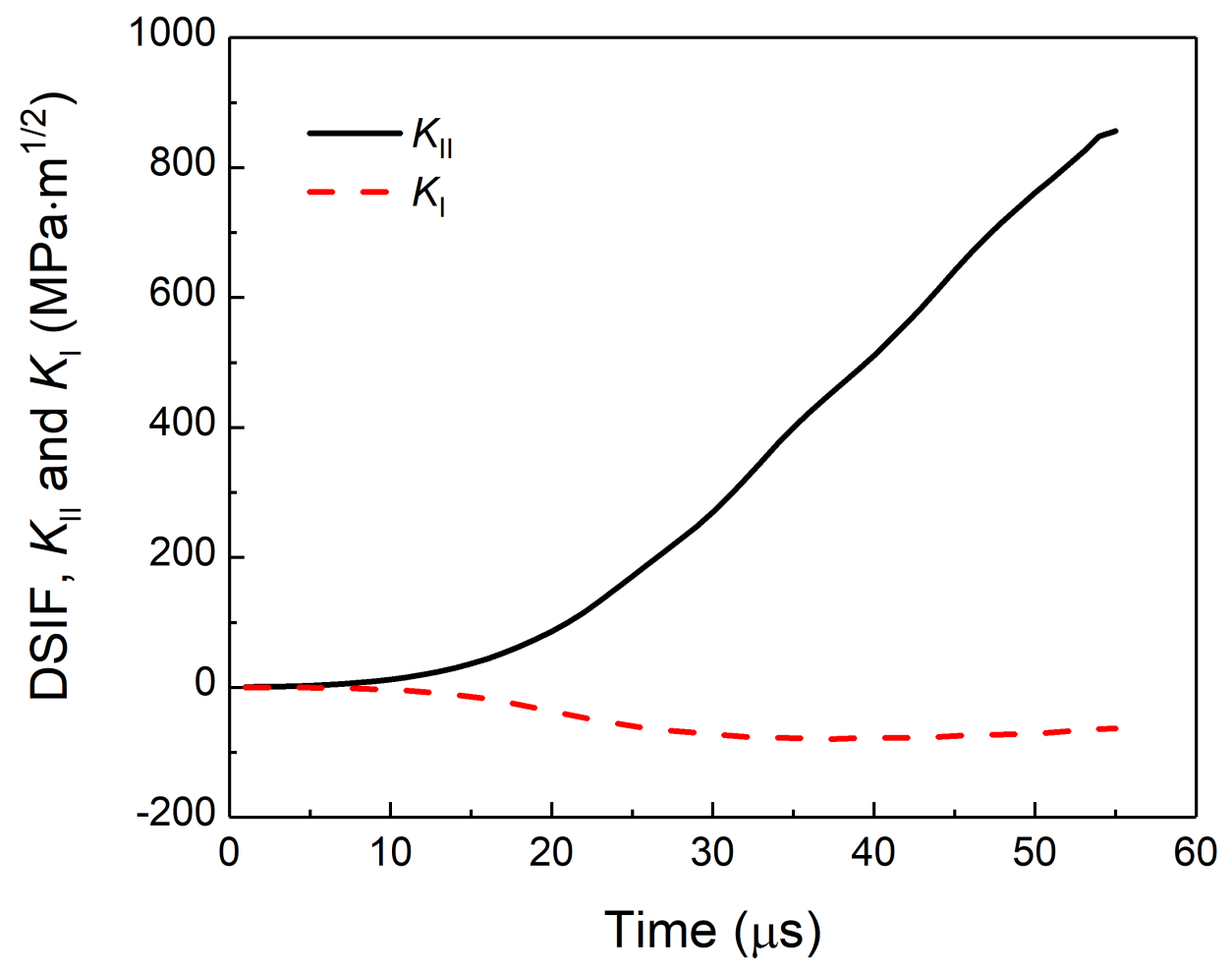

Figure 17. Time histories of mode I and mode II dynamic stress intensity factors (DSIFs).

Using the measured/predicted fracture initiation time, the mode II DFT ( $\left.K_{\text {IId }}\right)$ can be determined from the $K_{\mathrm{II}}(t)$ curve obtained for each test. In our experiments, the loading rate is controlled by the velocity of the striker bar (Fig. 2a). Its relationship with the fracture initiation time and loading rate is plotted in Fig. 18. It can be seen that the loading rate has a significant positive correlation with the striker bar velocity, whilst the fracture initiation time gradually shortens with increasing striker bar velocity. This suggests that the loading rate on the crack tip can be controlled precisely with the proposed $2 \mathrm{SF}$ specimen and $2 \mathrm{~B} / 2 \mathrm{SI}$ loading technique. With increasing impact velocity, the specimen is subjected to greater amplitude of the incident stress wave, and the compression on the loading section of the specimen translates to higher loading rates at the crack tips. Figure 18 shows that the loading rate decreases gradually with fracture initiation time, implying that the transient loading rate $\dot{K}_{\mathrm{II}}$ is a good indicator of the rate of change of $K_{\mathrm{II}}$ at the initiation of fracture. The obvious tendency of the DFT to increase with loading rates is shown in Fig. 19.

To further elucidate how fracture toughness of the material changes for a broad range of loading rate, quasi-static tests (performed using an MTS testing machine) were carried out at various crosshead speed corresponding to loading rates between $1.10 \times 10^{-2}-1.74 \times 10^{3}\left(\mathrm{MPa} \cdot \mathrm{m}^{1 / 2} \mathrm{~s}^{-1}\right)$. The 
fracture toughness $K_{\text {IIc }}$ in these tests were determined using the same method as described above. Both the quasi-static and the dynamic results were plotted together in Fig. 20. A linear fit is proposed for the quasi-static regime whereas an exponential fit is used for its dynamic counterpart. At the lower rates, $K_{\text {IIc }}$ increases gradually (and linearly). Beyond $10^{6}\left(\mathrm{MPa} \cdot \mathrm{m}^{1 / 2} \mathrm{~s}^{-1}\right), K_{\text {IId }}$ increases exponentially under dynamic conditions. This suggests that the failure process in the material is dominated by different mechanisms for low and high loading rates.

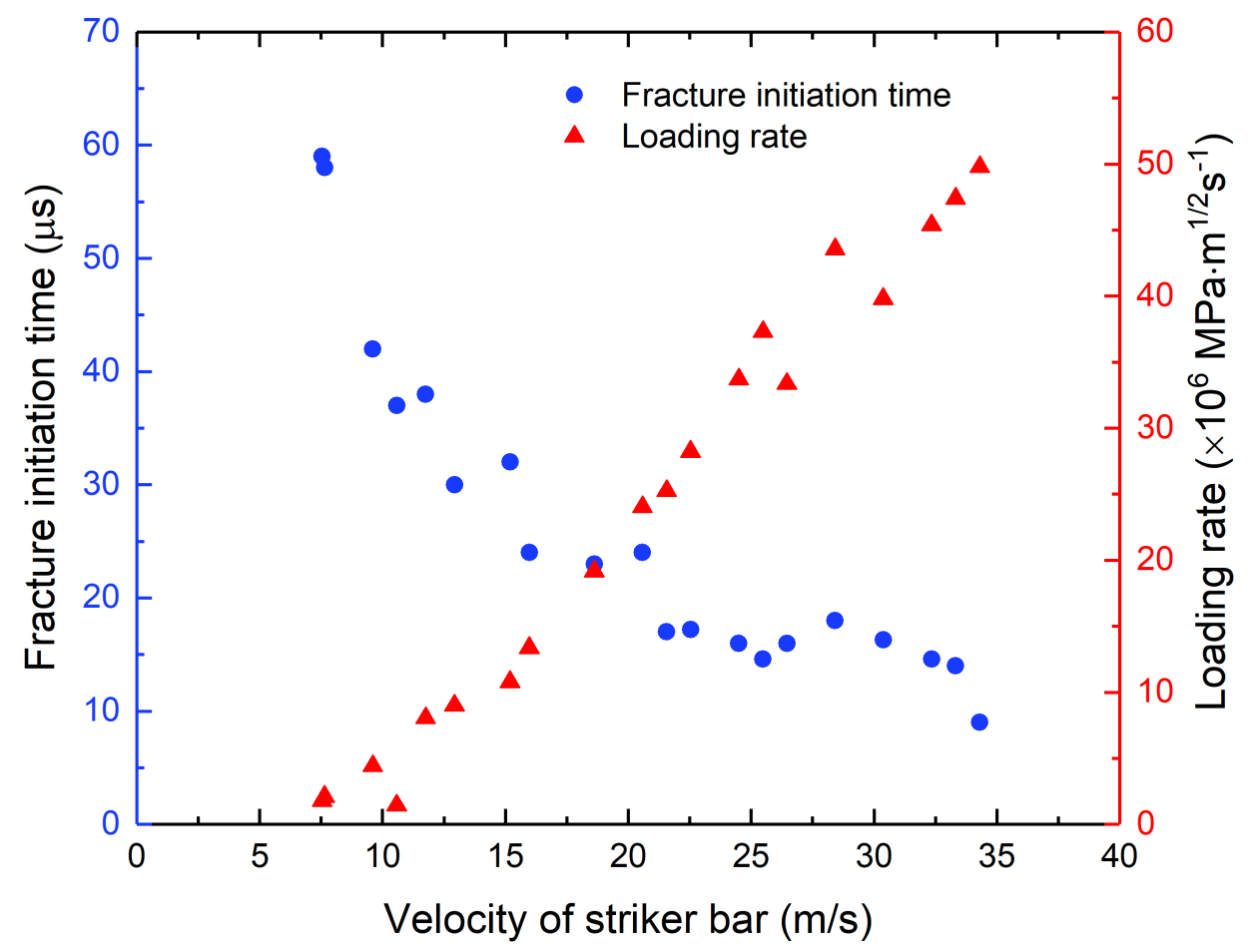

Figure 18. Relationship between fracture initiation times and loading rates with the striker bar velocity. 


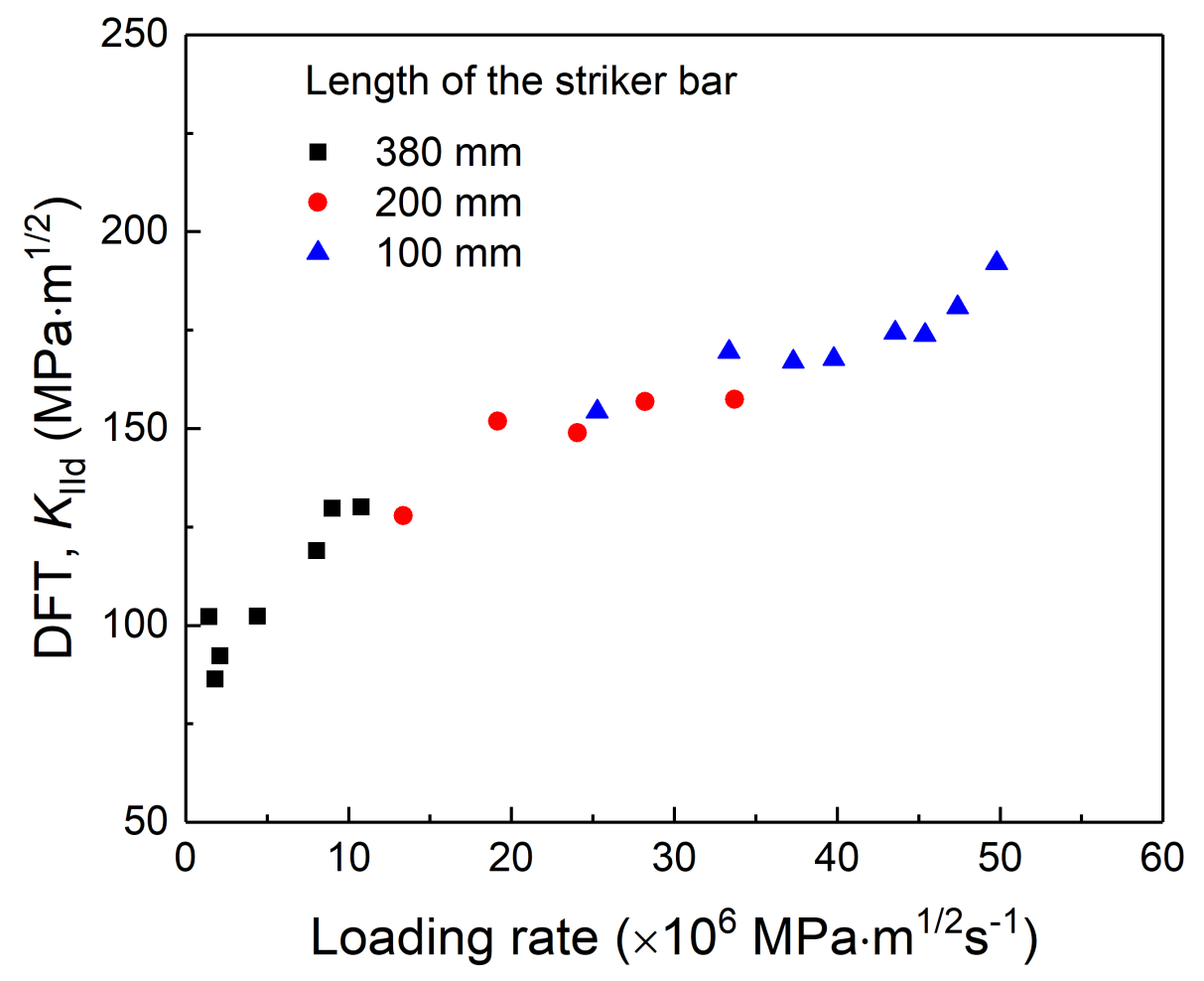

Figure 19. Variation of the mode II dynamic fracture toughness (DFT) with loading rate.

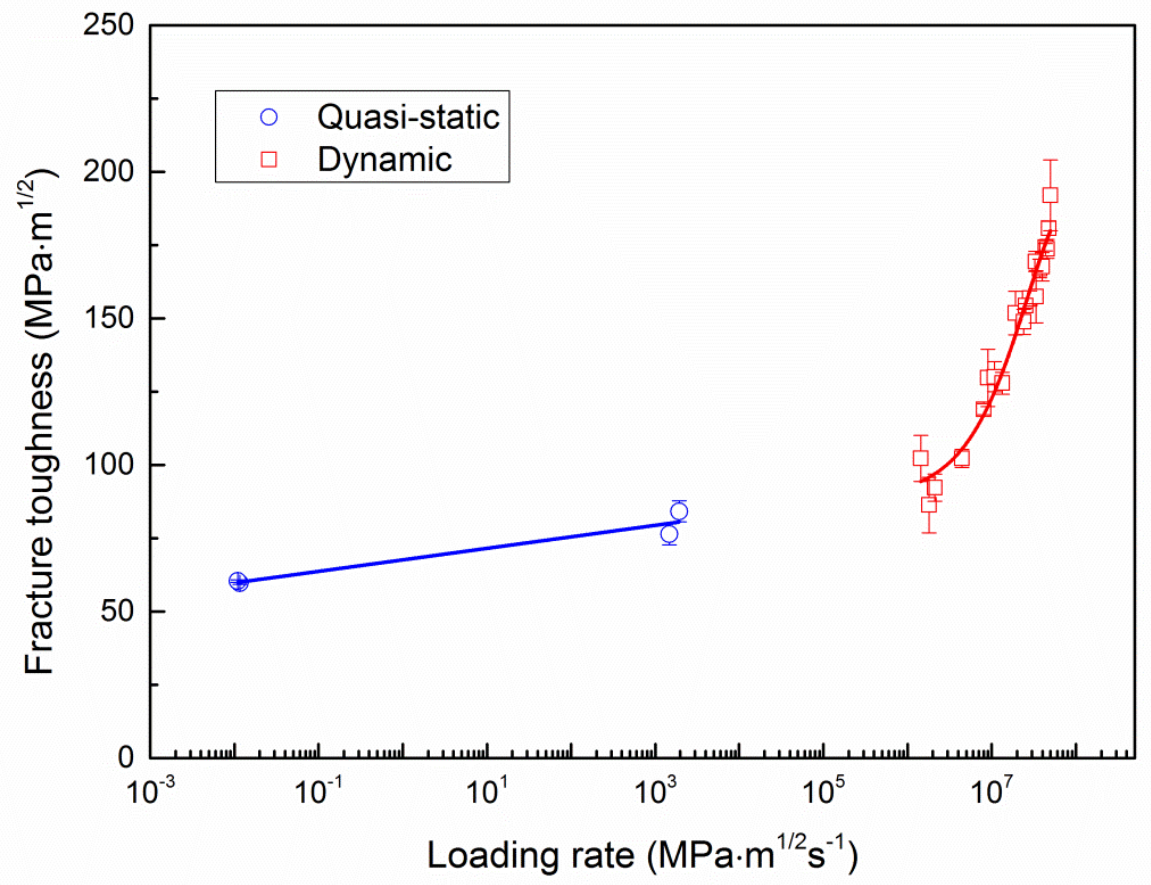

Figure 20. Variation of mode II dynamic fracture toughness (DFT) as a function of loading rate. 


\section{Fractographic examination}

In this section, we employ the fractographic method (using SEM) to elucidate the different modes of failure through examination of the fractographic features and its influence upon the DFT that were measured.

Figs. 21 and 22 show the typical fracture morphology obtained under quasi-static loading conditions. At $1.10 \times 10^{-2} \mathrm{MPa} \cdot \mathrm{m}^{1 / 2} \mathrm{~s}^{-1}$, the fracture surface (Fig. 21a) exhibit typical features associated with brittle cleavage fracture, as exemplified by the large proportion of smooth and flat regions with 'river-like' patterns. Elsewhere, some rough surfaces and layered structures are also observed on the surface. Fig. 21b shows a magnified view of region A in Fig. 21a. It showed that this region is permeated by many shear dimples that were piled up at the junction of various layers. The bright boundaries were a consequence of the coalescence of adjacent dimples. Some of these dimples are slightly elongated, whilst others appear nearly equiaxed. The shear dimples in region C exhibit a wide variety of sizes - they are obvious from Fig. 21c. Many sub-dimples and microvoids were also present alongside larger-sized voids. A magnified view of the flat region B in Fig. 21a is shown in $21 \mathrm{~d}$. This area is covered by numerous lamellar structures, characteristic of different cleavage planes. However, the features along the edges of these lamellar structures show very shallow dimple-like characteristics. In general, the fractography shows that, at this loading rate, the fracture extends in a mixed brittle-ductile mode. Along the shear plane, the main crack surface exhibits brittle characteristics; at the edges and junction areas of different layers, however, the fracture exhibits typical ductile characteristics.

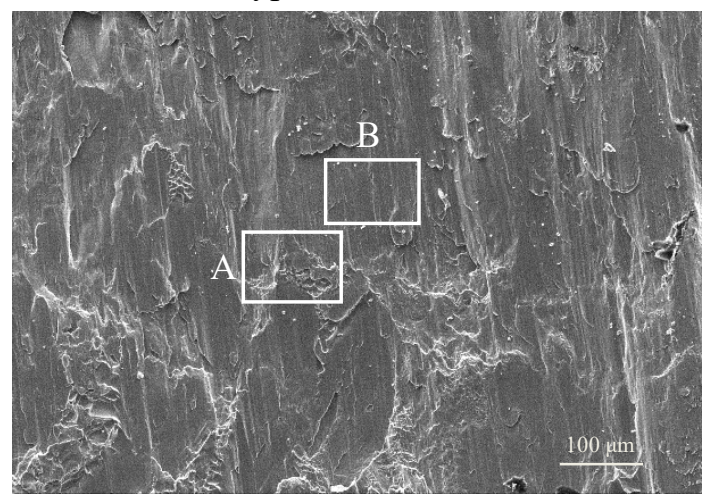

(a)

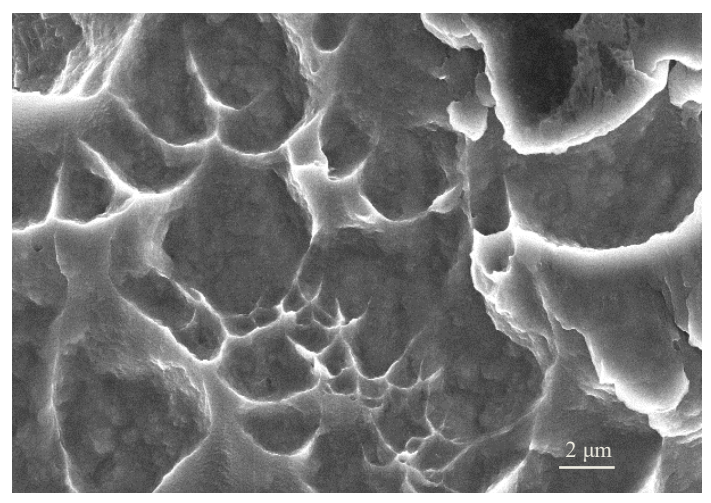

(c)

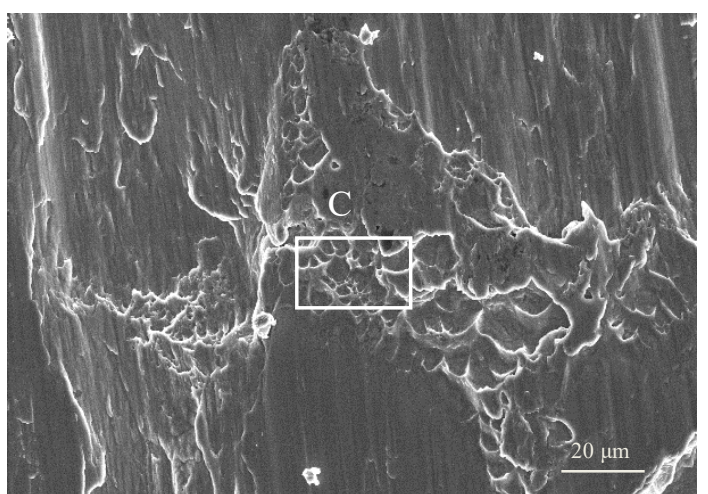

(b)

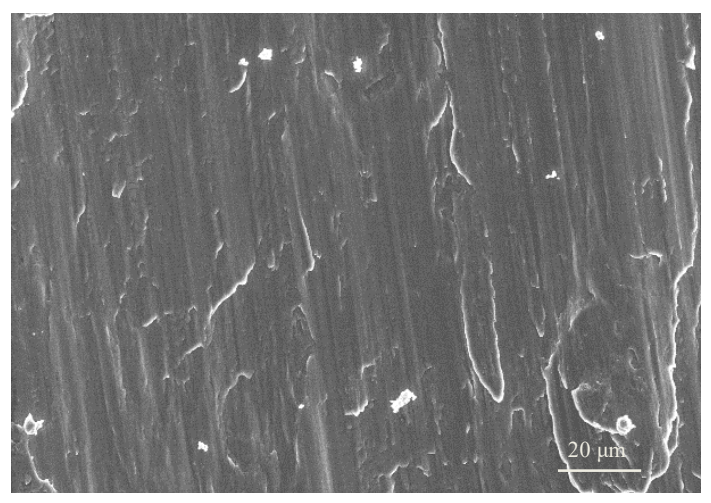

(d)

Figure 21. Fracture morphologies of the material under quasi-static loading condition $\left(1.10 \times 10^{-2} \mathrm{MPa} \cdot \mathrm{m}^{1 / 2} \mathrm{~s}^{-1}\right)$ : (a) smooth and flat regions (section B) and rough areas and layered structures (section A) coexist in the fracture surface; (b) magnified view of section A; (c) magnification of section C; (d) magnification of section B 
When loading rate is increased to $1.50 \times 10^{3} \mathrm{MPa} \cdot \mathrm{m}^{1 / 2} \mathrm{~s}^{-1}$, the flat and smooth areas (in Fig. 22a), highlighted previously in Fig. 21a, reduces dramatically. By contrast, more serrated and uneven regions were observed on the fractured surface, which is covered by a lot of shear dimples. A highermagnification view of the area in Fig $22 \mathrm{~b}$ shows that there are a large number of fine dimples that are densely distributed on the surface. At the edges of the serrations, some secondary cracks can clearly be seen (indicated by the red arrows). More offset facets were observed, showing an appearance of quasi-cleavage steps. All these features indicate that, at higher loading rates, there also exists a mixed, brittle-ductile, fracture mode; however, ductile fracture plays a more dominant role.

At the lower loading rates, the fractured surface grew mainly through the coalescence of voids and microcracks. Depending on the triaxial stress state, the micro-mechanisms of plastic deformation can differ greatly. If voids are present at high stress triaxiality, they tend to enlarge and induce ductile failure by coalescence of neighbouring voids. At the lower stress triaxialities, however, the voids flattened out into micro-cracks which can interact, and coalesce, with neighbouring micro-cracks (Tvergaard, 2009, 2012; Dahl et al., 2012). Under intense shear loading, such as in the present work, plastic deformation, however, takes place with minimum void growth. With a slow loading, the microcracks form and extend in the same shear plane, where the stress triaxiality is close to zero. At some point the specimen breaks catastrophically through cleavage fracture to form the large flat areas with very shallow dimple-like features at the layer boundaries. Along this shear plane, the fracture process is predominantly brittle in character. At the interface of different microcracks, the material is in a state of higher stress triaxiality, and the voids can be stretched to some extent before their coalescence. At higher loading rates, however, the voids have less time to grow and coalesce to form larger microcracks and flat areas. Much more serrations and a larger number of dimples were generated on the fractured surface compared to the lower loading rates, due to the coalescence of adjacent dimples and microcracks. Therefore, along these places the fracture exhibits more ductile characteristics, and more energy is absorbed through the formation of dimples and steps. This may also explain why the DFT increases with the loading rates, albeit at a lower rate of increase, under quasi-static loadings.

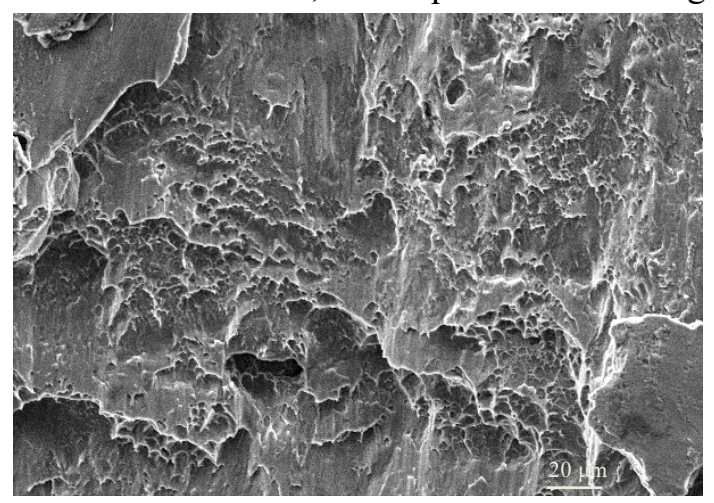

(a)

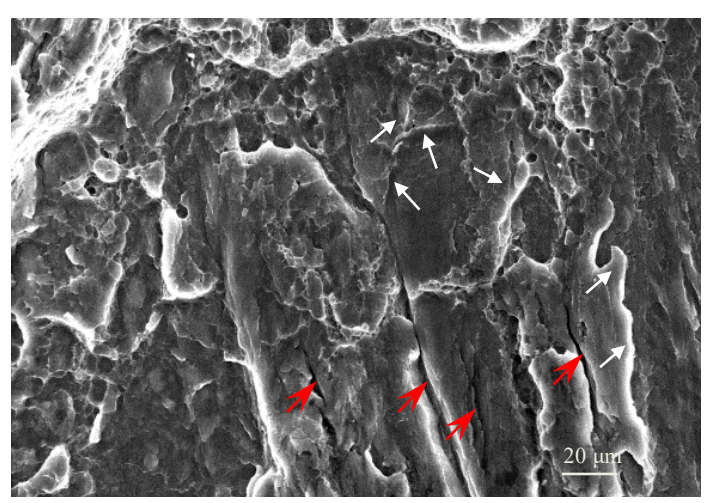

(b)

Figure 22. Fracture morphologies of the material under the quasi-static loading condition $\left(1.50 \times 10^{3} \mathrm{MPa} \cdot \mathrm{m}^{1 / 2} \mathrm{~s}^{-}\right.$ ${ }^{1}$ ): (a) serrations and uneven regions covered by shear dimples; (b) fine dimples at the top right corner, some offset facets are shown by white arrows, and secondary cracks are indicated by red arrows.

Under dynamic loading, the fractured surfaces present entirely different morphologies compared to its quasi-static counterpart. At $4.42 \times 10^{6} \mathrm{MPa} \cdot \mathrm{m}^{1 / 2} \mathrm{~s}^{-1}$, the fractured surface was densely 
covered with 'scaled-like' patterns - see Fig. 23a. Enlarged view showed that these 'scaled-like' patterns in Fig. 23b are actually severely elongated shear dimples. Flow patterns (indicated by white arrows) were also clearly visible in the direction of the shear load which indicates that, under dynamic loading, thermal softening plays a dominant role in the failure process. Due to the high strength, low thermal conductivity and low strain hardening rate of the Ti-6Al-4V alloy, the specimen is highly susceptible to the formation of adiabatic shear bands under high strain rates. With rapid temperature rises in the shear zone, the material tends to flow within a slip plane; plastic deformation is highly concentrated in this plane, where multiple ASBs arise and intersect. In the shear bands, the dimples were stretched so severely, leading to the formation of the 'scaled-like' patterns. In Fig. 23c, some relatively smooth and smeared regions were present in conjunction with the elongated dimples. Characteristic plastic flow patterns were also obvious - these are indicated by the white arrows. These regions were induced by contact between the sliding surfaces of the ASB, leading to material melting inside the shear bands. We also observed, in the high-speed images, sparkles that were ejected from the shear zone during the formation of new fracture surfaces. These sparkles are melted droplets ejected by the ASB under high speed shearing. Fig. 24 shows that with the increase of the loading rates, the amount of these droplets also increases, a direct consequence of the greater amount of melted material with increasing loading rate. This means that with increasing loading rates, more of the energy from the deformation is converted into heat because of strain rate/strain hardening effect of the material; meanwhile, less heat is transferred into the adjacent material or the environment and, therefore, the temperature rise is more significant in the shear band. Consequently, more energy is dissipated since yielding and plastic deformation are more pronounced along the crack propagation path due to thermal-softening effect. Therefore, the fracture toughness shows a steep rise in Fig. 20 for dynamic loading conditions.

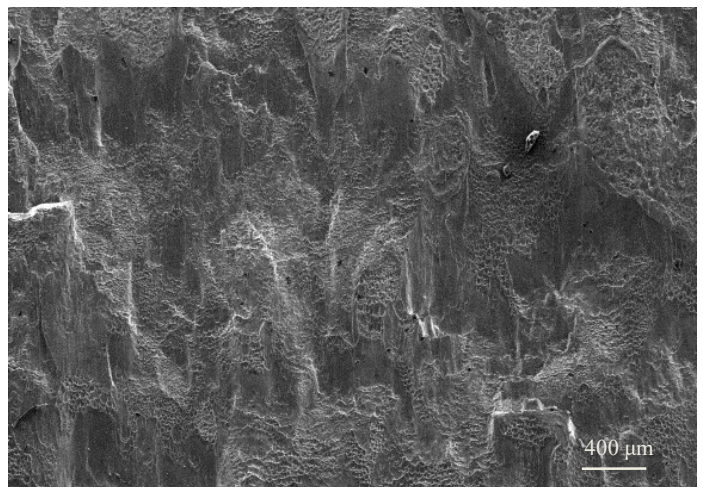

(a)

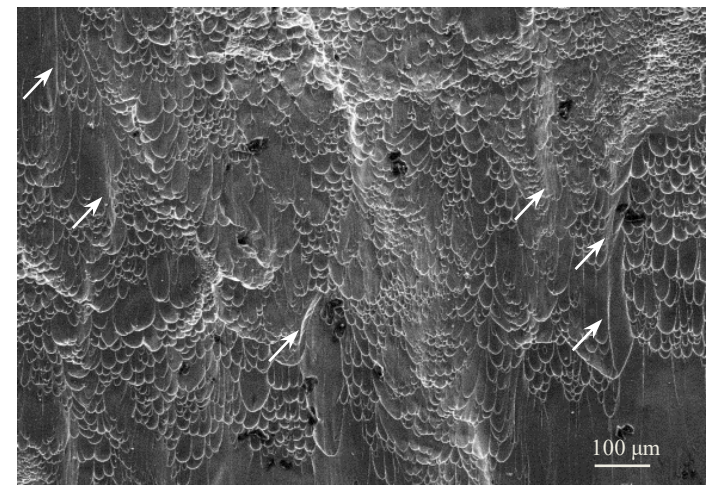

(b)

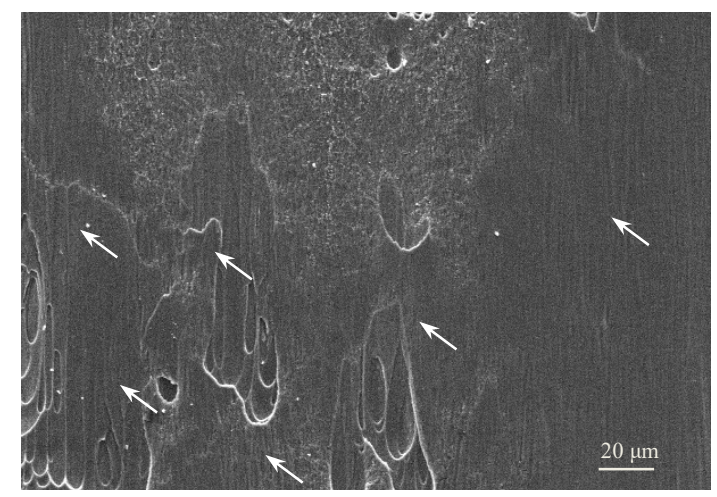

(c) 
Figure 23. Fracture morphologies of the material under the dynamic loading condition $\left(4.42 \times 10^{6} \mathrm{MPa} \cdot \mathrm{m}^{1 / 2} \mathrm{~s}^{-1}\right)$ : (a) thick 'scaled-like' patterns covered the fracture surface; (b) magnified view of Fig. 24(a) where flow patterns are indicated by arrows; and (c) relatively smooth and smeared regions (arrows) in conjunction with the elongated dimples.

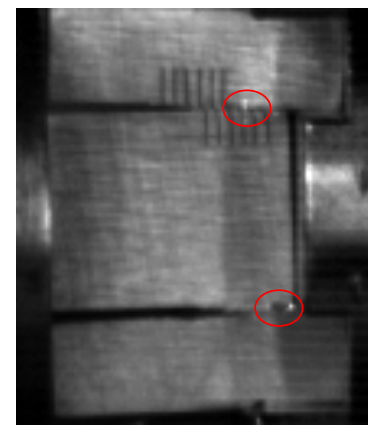

(a)

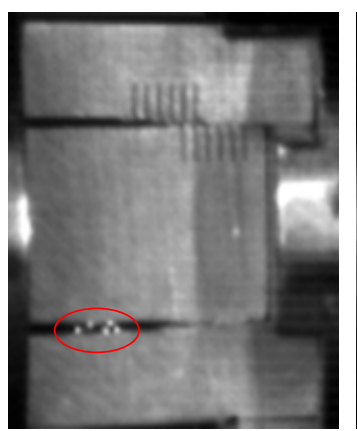

(b)

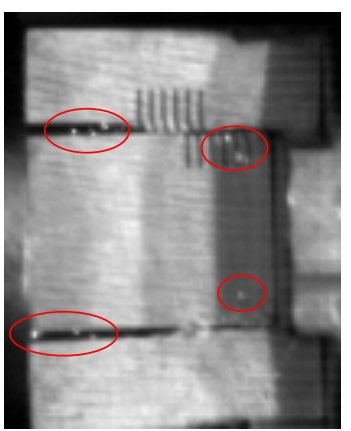

(c)

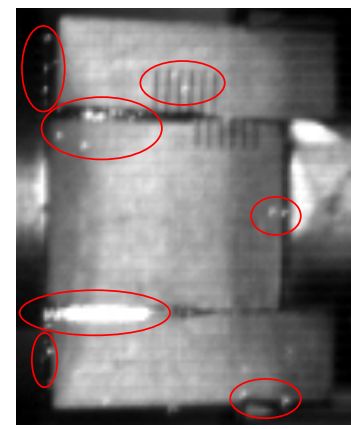

(d)

Figure 24. Increasing melted material at loading rates of (a) $9.01 \times 10^{6} \mathrm{MPa} \cdot \mathrm{m}^{1 / 2} \mathrm{~s}^{-1}$, (b) $1.08 \times 10^{7} \mathrm{MPa} \cdot \mathrm{m}^{1 / 2} \mathrm{~s}^{-1}$, (c) $2.82 \times 10^{7} \mathrm{MPa} \cdot \mathrm{m}^{1 / 2} \mathrm{~s}^{-1}$, and (d) $4.74 \times 10^{7} \mathrm{MPa} \cdot \mathrm{m}^{1 / 2} \mathrm{~s}^{-1}$. All photos were taken $306 \mu$ s from the start of the dynamic loading. The sparkles in the circled regions are droplets of melted material.

It was previously reported by Kalthoff and Wrinkler (1988), Kalthoff (2000) and Kalthoff and Bürgel (2004) that a failure mode transition, from tensile crack to ASB, occurs when the loading rate exceeds a critical level. We showed in this paper that ASB is, indeed, the primary mode of failure at high loading rates through post-test examination of recovered specimens, where features of ASBs were observed throughout the ligament of our specimens. Unlike previously, both DSF and ASB were observed during the same loading event. The failure of the specimen is controlled by the interactions, and is a competition, between continued shear fracture and development of ASBs. The continuation of shear fracture is eventually surpassed by the effects of ASB, and further progression by shear fracture is inhibited by the development of ASB or by the coalescence with it.

\section{Conclusion}

A $2 \mathrm{~B} / 2 \mathrm{SI}$ loading technique is used to study the mode II dynamic fracture properties of Ti-6Al$4 \mathrm{~V}$, which avoids the limitations of the one-point impact methods. Effects of loading rate on the mode II DFT and the micro-mechanisms were investigated. It was shown that fracture toughness increases gradually at the lower loading rates but increases rapidly beyond $10^{6} \mathrm{MPa} \cdot \mathrm{m}^{1 / 2} \mathrm{~s}^{-1}$. Fractography reveals a brittle-ductile mixed fracture mode under quasi-static loading. As loading rate increases, more shear dimples and quasi-cleavage appear in the fractured surfaces, revealing an increasing significant role played by ductile fracture. Under dynamic loading, elongated dimples and flowing patterns are the primary features of the fractured surface where ASB-induced fracture is the dominant failure mode. Both DSF and ASB develops simultaneously, and interacts with each other, in the ligament. Crack initiation occurs without interference from the ASB initially and grows at an inclined angle towards the center of the specimen. Further propagation of the cracks in the specimen are shown to be governed by interactions between the DSF and ASB, where the DSF either coalesces with the ASB or is interrupted by the development of a new fracture within the ASB. The results and observations presented in this paper will be helpful in the failure analysis/design of engineering structures; and, provide a new understanding of the interplay between DSF and ASB. 


\section{Acknowledgments}

The authors gratefully acknowledge the financial support by the National Natural Science Foundation of China (No. 11772062, 12072040) and the China Scholarship Council. This work is also partially supported by the State Key Laboratory of Explosion Science and Technology (YBKT19-08).

\section{References}

Arriaga, M., Waisman, H., 2017. Combined stability analysis of phase-field dynamic fracture and shear band localization. Int. J. Plast. 96, 81-119

Chen E.P., Sih G.C., 1977. Transient response of cracks to impact loads. In: Mechanics of Fracture, Vol. 4, Elastodynamic Crack Problems (Edited by G. C. Sih), Leyden: Noordhoff, 1-58.

Dahl J., Nielsen, K.L., Tvergaard, V., 2012. Effect of contact conditions on void coalescence at low stress triaxiality shearing. ASME J. Appl. Mech. 79, 021003-1-7.

Dong, X., Wang, L., Yu, J., 2003. An investigation on shear fracture under impact loading. J. Ningbo University (NSEE) 16, 429433.

Dong, X., Yu, J., Hu, S., Wang, W., Wang, L., 1998. Stress intensity factor and fracture behavior for mode II crack specimen under high shear loading rate. Explosion and Shock Waves 18, 62-68. (in Chinese)

Guduru, P.R., Rosakis A.J., Ravichandran, G., 2001. Dynamic shear bands: an investigation using high speed optical and infrared diagnostics. Mech. Mater. 33: 371-402

Jiang, F., Vecchio, K.S., 2009. Hopkinson bar loaded fracture experimental technique: a critical review of dynamic fracture toughness tests. Applied Mechanics Reviews 62, 060802.

Kalthoff, J.F., 1987. Shadow optical analysis of dynamic shear fracture. SPIE, Photomechanics and Speckle Metrology 814, 531538.

Kalthoff, J.F., 1990. Transition in the failure behavior of dynamically shear loaded cracks. Proceedings of the $11^{\text {th }}$ U.S. National Congress of Applied Mechanics (ed. Chen, D.F.), Tucson, Arizona, May 21-25 1990, also Applied Mechanics Review 43, s247-s250.

Kalthoff, J.F., 2000. Modes of dynamic shear failure in solids, Int. J. Fract. 101, 1-31.

Kalthoff, J.F., Bürgel, A., 2004. Influence of loading rate on shear fracture toughness for failure mode transition. Int. J. Impact Eng. $30,957-971$.

Kalthoff, J.F., Wrinkler, S., 1988. Failure mode transition at high rates of shear loading. Impact loading and dynamic behavior of materials (ed. Chiem, C.Y., Kunze, H.-D. and Meyer, L.W.), Vol. 1, pp. 185-195.

Kusaka, T., Yamauchi, Y., Kurokawa, T., 1994. Effects of strain rate on mode II interlaminar fracture toughness in carbonfibre/epoxy laminated composites. Journal de Physique IV 4(C8), 671-676

Lee YJ, Freund LB (1990) Fracture initiation due to asymmetric impact loading of an edge cracked plate. J Appl Mech 57: 104

Lin, Q., Wang, S., Pan, P.-Z., Ji, W-W, Lu, Y., 2020. Fracture initiation under pure shear revisited: Remarks on the $\mathrm{m}$ ode II fracture in quasi-brittle materials. Theoretical and Applied Fracture Mechanics, Volume 109, October 2020, 102700.

Liu, R., Hui, S., Ye, W., Mi, X., Xiong, B., You, Z., 2010. Study on dynamic fracture behavior of TA15ELI alloy under mode II loading by caustics method. Rare Metals 29, 361-365.

Mason, J.J., Lambros, J., Rosakis, A.J., 1992. The use of a coherent gradient sensor in dynamic mixed-mode fracture mechanics experiments. J. Mech. Phys. Solids 40, 641-661.

Mason, J.J., Rosakis, A.J., Ravichandran, G., 1994. Full field measurements of the dynamic deformation field around a growing adiabatic shear band at the tip of a dynamically loaded crack or notch. J. Mech. Phys. Solids 42, 1679-1697.

Miao, R., Wang, W., Song, Y., 2016. Research on relationship between crack propagation speed of TC4 alloy and loading speed under mode II dynamic loading. Acta Armamentarii 37, 2231-2239. (in Chinese)

Nakano, M., Kishida, K., Yamauchi, Y., Sogabe, Y., 1994. Dynamic fracture initiation in brittle materials under combined mode I/II loading. Journal de Physique IV 4(C8), 695-700

Nemat-Nasser, S., Isaacs, J.B., Starrett, J.E., 1991. Hopkinson techniques for dynamic recovery experiments. Proc. R. Soc. Lond. A 435, 371-391.

Nwosu, S.N., Hui, D., Dutta, P.K., 2003. Dynamic mode II delamination fracture of unidirectional graphite/epoxy composites. Composites: Part B 34, 303-316. 
Ravi-Chandar, K., 1995. On the failure mode transitions in polycarbonate under dynamic mixed-mode loading. Int. J. Solids Structures 32, 925-938

Rittel, D., 2005. A hybrid experimental-numerical investigation of dynamic shear fracture. Engng. Fract. Mech. 72 , $73-89$.

Rittel, D., 1998. The influence of temperature on dynamic failure mode transitions. Mechanics of Materials 30, $217-227$.

Rittel, D., Levin, R., Maigre, H., 1997. On dynamic crack initiation in polycarbonate under mixed-mode loading. Mechanics Research Communications 24, 57-64.

Rittel, D., Maigre, H., 1996. A study of mixed-mode dynamic crack initiation in PMMA. Mechanics Research Communications $23,475-481$.

Rittel, D., Zhang, L.H., Osovski, S., 2017 The dependence of the Taylor-Quinney coefficient on the dynamic loading mode. Journal of the Mechanics and Physics of Solids, 107: 96-114.

Roessig, K.M., Mason J.J., 1998. Adiabatic shear localization in the impact of edge-notched specimens. Experimental Mechanics 38, 196-203.

Seo S, Min O, Yang H. Constitutive equation for Ti-6Al-4V at high temperatures measured using the SHPB technique. Int. J. Impact. Eng, 2005, 31(6):735-754

Sohn, M.S., Hu, X.Z., 1996. Impact and high strain rate delamination characteristics of carbon fibre epoxy composites. Theoretical and Applied Fracture Mechanics 25, 17-29.

Srinath, L.S., Murthy, Srinivasa Murthy, N., Hareesh, T.V., 1983. Determination of stress-intensity factors for cracks in tubes under torsion. Experimental Mechanics 23, 262-267.

Tvergaard, V., 2009. Behavior of voids in a shear field. Int. J. Fracture 158: 41-49

Tvergaard, V., 2012. Effect of stress-state and spacing on voids in a shear-field. Int. J. Solids Structures 49: 3047-3054

Wen, X., Lu, F., Cao, L., Lin, Y., 2016. Experimental studies on mixed-mode dynamic fracture behaviour of aluminium alloy plates with narrow U-notch. Fatigue Fract. Engng. Mater. Struct. 39, 1379-1390.

Xu, Z., Li, Y., Liu, Y., Luo, J., Chen, Y., 2006. Mode II dynamic fracture toughness of two high strength steels under high loading rate. Acta Metallurgica Sinica, 42, 635-640. (in Chinese)

$\mathrm{Xu}, \mathrm{Z}$., Li, Y., 2011. Dynamic fracture toughness of high strength metals under impact loading: increase or decrease. Acta. Mech. Sin. 27(4): 559-566

$\mathrm{Xu}, \mathrm{Z}$., Li, Y., 2012. A novel method in determination of dynamic fracture toughness under mixed mode I/II impact loading. Int. J. Solids Structures 49: 366-376

Xu, Z., Li, Y., Huang, F., 2012. Application of split Hopkinson tension bar technique to study of dynamic fracture properties of materials. Acta Mechanica Sinica 28(2): 424-431.

Xu, Z., He, X., Han, Y., Huang, F., 2020. A different viewpoint on mechanism of fracture to shear-banding failure mode transition. Journal of the Mechanics and Physics of Solids, 145: 104165

Xu, Z., He, X., 2018. A New Method to Determine Dynamic Fracture Toughness of Pure Mode II at High Loading Rates. $17^{\text {th }}$ Asian Conference on Experimental Mechanics, Xi'an, China, Oct. 11-15, 2018.

Yao, W., Xu, Y., Yu, C., Xia, K., 2017. A dynamic punch-through shear method for determining dynamic Mode II fracture toughness of rocks. Engng. Fract. Mech. 176, 161-177.

Zhou, M., Rosakis, A.J., Ravichandran, G., 1996. Dynamically propagating shear bands in impact-loaded prenotched plates-I. Experimental investigations of temperature signatures and propagation speed. J. Mech. Phys. Solids 44, $981-1006$.

Zou, G., Chen, H., Chang, Z., 2017. A modified mode II dynamic fracture test technique based on SHTB. Chinese Journal of Theoretical and Applied Mechanics 49, 117-125. 